\title{
Spillovers of US unconventional monetary policy: quantitative easing, spreads, and international financial markets
}

\author{
Zekeriya Yildirim $^{1^{*}}$ (10 and Mehmet Ivrendi
}

\author{
${ }^{*}$ Correspondence: \\ zekeriyayildirim@anadolu. \\ edu.tr \\ 1 Department of Economics, \\ Faculty of Economics \\ and Administrative Sciences, \\ Anadolu University, Tepebasi, \\ Eskisehir 26470, Turkey \\ Full list of author information \\ is available at the end of the \\ article
}

\begin{abstract}
This study investigates the international spillover effects of US unconventional monetary policy (UMP) - frequently called large-scale asset purchases or quantitative easing (QE) —on advanced and emerging market economies, using structural vector autoregressive models with high-frequency daily data. Blinder (Federal Reserve Bank of St. Louis Rev 92(6): 465-479, 2010) argued that the QE measures primarily aim to reduce US interest rate spreads, such as term and risk premiums. Considering this argument and recent empirical evidence, we use two spreads as indicators of US UMP: the mortgage and term spreads. Based on data from 20 emerging and 20 advanced countries, our empirical findings reveal that US unconventional monetary policies significantly affect financial conditions in emerging and advanced countries by altering the risktaking behavior of investors. This result suggests that the risk-taking channel plays an important role in transmitting the effects of these policies to the rest of the world. The extent of these effects depends on the type of QE measures. QE measures such as purchases of private sector securities that lower the US mortgage spread exert stronger and more significant spillover effects on international financial markets than those that reduce the US term spread. Furthermore, the estimated financial spillovers vary substantially across countries and between and within the emerging and advanced countries that we examine in this study.
\end{abstract}

Keywords: US unconventional monetary policy, Quantitative easing, Interest rate spreads, Emerging markets, Financial spillovers, SVAR

JEL Classification: E43, E44, E52, E65, F42

\section{Introduction}

In response to the great recession in 2007-2009, the Federal Reserve (the Fed) used conventional and unconventional monetary policy (UMP) instruments. Figure 1 depicts these instruments and shows that the Fed began to lower the federal funds rate-a conventional monetary policy instrument. After several cuts, at the end of 2008, the rate reached the zero bound (shown by the dashed red line on the right side of Fig. 1). This phenomenon indicates that the Fed cannot do anything to get the economy out of the great recession by using its conventional monetary policy tool. The Fed, then, used UMP

(c) The Author(s), 2021. Open Access This article is licensed under a Creative Commons Attribution 4.0 International License, which permits use, sharing, adaptation, distribution and reproduction in any medium or format, as long as you give appropriate credit to the original author(s) and the source, provide a link to the Creative Commons licence, and indicate if changes were made. The images or other third party material in this article are included in the article's Creative Commons licence, unless indicated otherwise in a credit line to the material. If material is not included in the article's Creative Commons licence and your intended use is not permitted by statutory regulation or exceeds the permitted use, you will need to obtain permission directly from the copyright holder. To view a copy of this licence, visit http:// creativecommons.org/licenses/by/4.0/. 


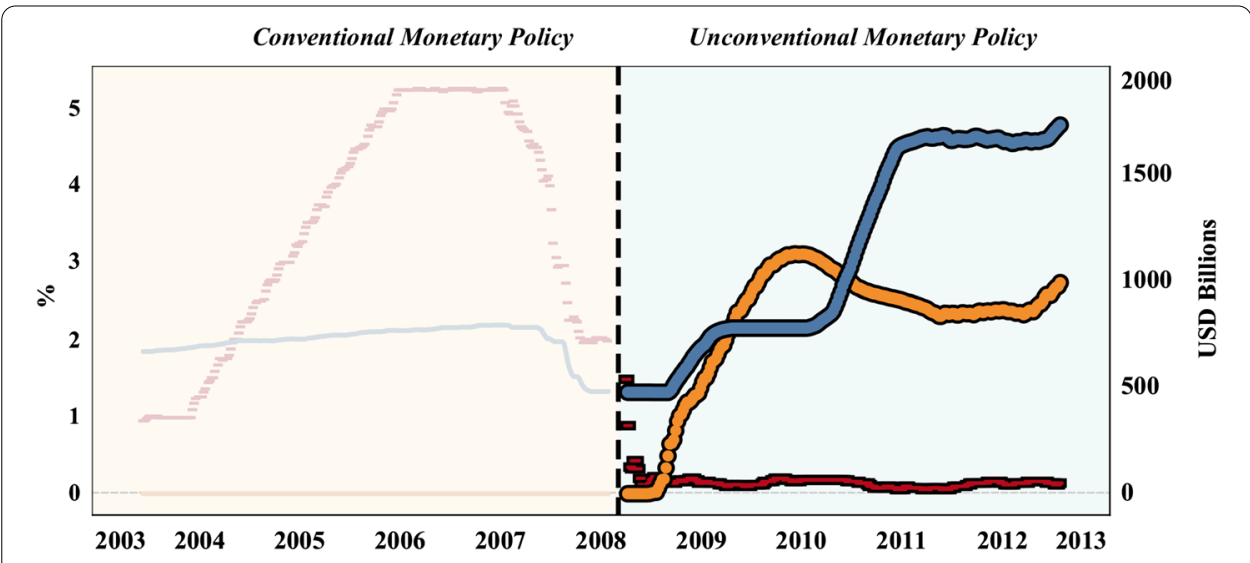

Fig. 1 US monetary policy instruments: Conventional: The Federal Funds Rate is initially colored light red and then dark red (left scale); Unconventional: The Fed's TS and MBS holdings are initially colored light blue and orange and then dark blue and orange (right scale), respectively

instruments-so-called large-scale asset purchases (LSPAs) or quantitative easing (QE) and forward guidance-to stimulate economic activities. Thus, the Fed's balance sheet holdings of mortgage-backed securities (MBS) and treasuries (TS) sharply increased (the right panel of Fig. 1). The difference between conventional and unconventional US monetary policies is that conventional policy uses a short-term interest rate to affect financial conditions and the economy, whereas UMP uses QE and forward guidance as policy instruments. The present study focuses on a specific UMP measure conducted by the Fed, that is, QE.

Kuttner (2018) emphasized that the QE instrument refers to a set of four asset purchase programs: the three LSAPs, commonly known as QE1, QE2, and QE3, and the maturity extension program (MEP) (see Fig. 2 for the QE periods). During the QE1 period, the assets purchased by the Fed were agency debt, MBS, and TS at $\$ 1750$ billion. During the QE2 period, the assets purchased were longer-dated treasuries with a value of $\$ 600$ billion. During the MEP period, the assets purchased were 6-30-year treasuries with a value of $\$ 667$ billion. Furthermore, during the QE3 period, the purchased assets by the Fed were MBS and longer-dated treasuries at a value of $\$ 40$ and $\$ 45$ billion/ month, respectively. ${ }^{1}$

A sharp decline in the US interest rate spreads, particularly the mortgage spread, coincides with the period of US UMP (Fig. 2). This case raises the question of whether this decline in the spread can be attributed to US UMP.

\footnotetext{
${ }^{1}$ In addition to QE instruments, the Fed used forward guidance about future short-term interest rates to affect longerterm bond yields and other financial asset prices. The Fed can affect longer -term yields, which have two components: expectation and term premium components. The expectation component of the yields curve is the average of expected future short-term interest rates over the maturity of the longer-term bond. The term premium component includes compensation to investors for the risk of holding long-term bonds. The Fed's forward guidance aimed to push down expectations of future short rates, to reduce longer-term yields, and to influence financial conditions. Moreover, the Fed's forward guidance may also reduce interest rate volatility and uncertainty, which in turn reduces risk and term premia and further contributes to easier financial conditions. In that regard, Rudebusch (2018) provides evidence that forward guidance has generally been viewed as an effective policy tool to support the economic recovery.
} 


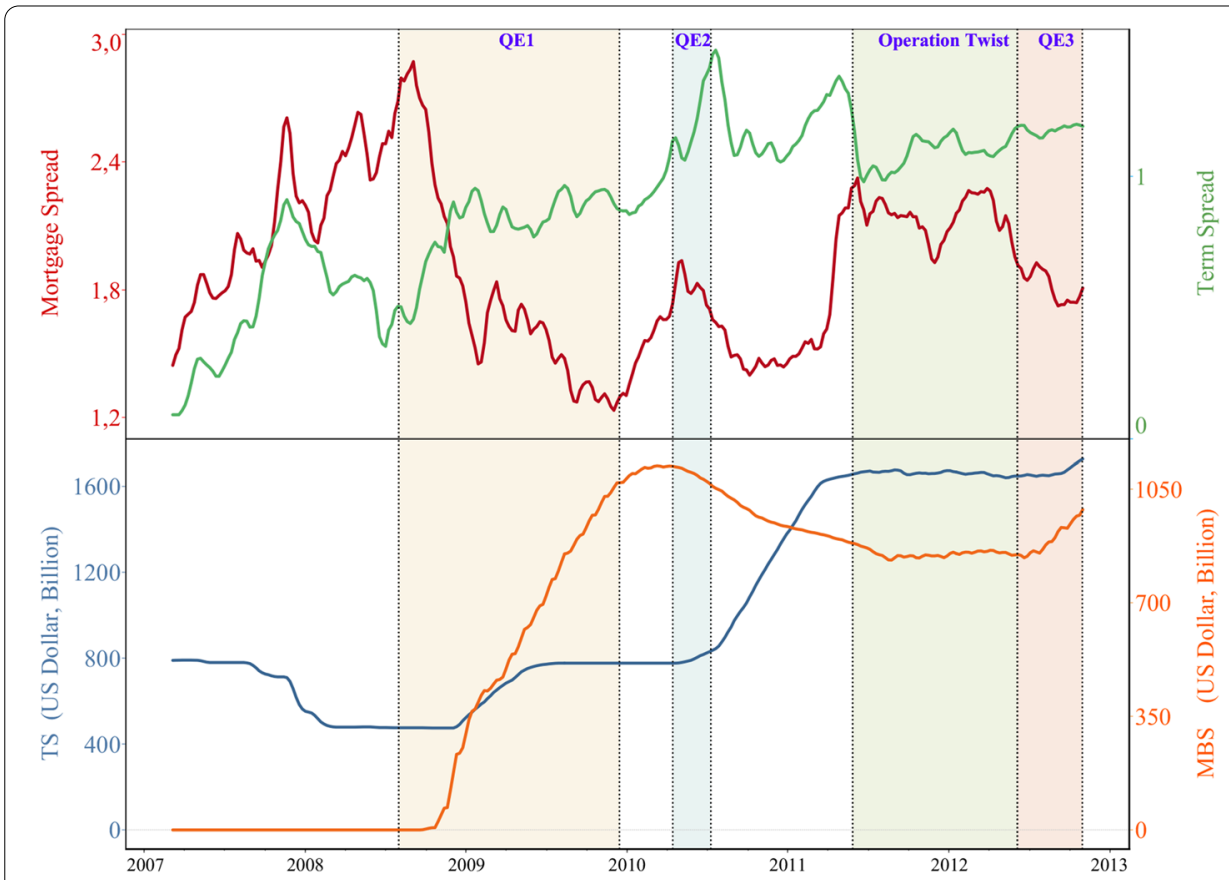

Fig. 2 Fed's quantitative easing policy (US UMP). Note: The US mortgage spread is calculated as the difference between the 30-year fixed rate mortgage rate and 10-year Treasury bond rate. The US term spread is also defined as the difference between 30-year and 10-year Treasury yields. MBS and TS represent the Fed's balance sheet holdings of MBS and TS, respectively. The QE1, QE2, operation twist, and QE3 span the periods, respectively: November 25, 2008 to April 11, 2010 (the QE1); August 10, 2010 to November 3, 2010(the QE2); September 21, 2011 to September 30, 2012(the operation twist); September 30, 20132 to February 24, 2013 (the QE3)

The answer provided by the recent studies is "yes". ${ }^{2}$ For instance, Hancock and Passmore (2011) reported that the Fed's MBS purchases have substantially reduced the mortgage spread.

Wang (2019) revealed that the Fed's market-based approach to UMP of providing direct financial support to the MBS market is effective in reducing MBS spreads. Additionally, Fig. 2 shows supportive evidence for this argument that the Fed's asset purchases substantially decreased the mortgage spread. This strong evidence on the tight link between US UMP (the Fed's asset purchases) and the spreads suggests that decreases in the spreads can be used as indicators of the effectiveness of UMP, ${ }^{3}$ which is consistent with the argument of Blinder (2010). He argued that the US UMP primarily aimed to reduce interest rate spreads, such as term and/or risk premiums. The reason was that "since private borrowing, lending, and spending decisions presumably depend on (risky) non-Treasury rates, reducing their spreads over (riskless) Treasuries reduces the interest rates that matter for actual transactions even if riskless rates are unchanged." Accordingly, UMP actions can be considered effective or successful if such actions remove risks from private securities and decrease costs of private borrowings, thereby

\footnotetext{
${ }^{2}$ See Nsafoah and Serletis (2020) for the effects of US conventional monetary policy on US interest rate spreads, the term spread and credit spread.

${ }^{3}$ See Wang (2019), Cheng and Chiu (2020), Feldkircher et al. (2020) and references therein.
} 
reducing spreads between private and government securities or among interest rates with different maturities.

In this paper, motivated by Blinder's (2010) argument and Hancock and Passmore (2011) and Wang (2019), we assess the international financial spillovers of US UMP by estimating the effects of a US mortgage spread shock on international financial markets and comparing them with those from a US term spread $^{4}$ shock. The US mortgage spread-defined as the difference between the interest rate on the mortgage and government securities-is considered an instrument for the counter cycle ${ }^{5}$ policy. Thus, the Fed chose to reduce the interest rate on the mortgage as a part of its UMP and started to purchase MBS to reduce the mortgage spread, which was very high before the great recession (Fig. 2). In other words, a US UMP measure, such as the Fed's purchases of MBS, intends to stabilize the US financial market and economy by decreasing the mortgage spread. The stabilizing role of the mortgage spread decline has been documented by two recent studies. First, Walentin (2014) revealed that negative mortgage spread shocks have significant expansionary effects on the US economy. Second, Cheng and Chiu (2020) looked at a different angle and analyzed the nonlinear effects of mortgage spread shocks on the economy. They reported that mortgage spread shocks have substantial effects on the US economy, which are much larger during recessions. They also revealed that these shocks can be interpreted as credit supply shocks in the mortgage market. Given the significant role of mortgage spread shocks on the US business cycle, one could expect that US mortgage spread shocks should also exert a substantial influence on foreign financial markets. However, to the best of our knowledge, no empirical study regarded the international financial effects of US mortgage spread shocks. ${ }^{6}$ The present study is the first to attempt to fill this gap. Additionally, to deepen our analysis, the term spread-defined as the gap between the long- and short-term interest rates of two securities with different maturities-is also considered a measure of UMP. Two factors make the term spread a good measure of US UMP, along with the mortgage spread. First, in the zero-lower-bound (ZLB) environment, the direct and observable consequence of US UMP is a fall in the term spread (see Blinder $(2010,2012)$ ). Thus, during the ZLB period, the term spread can accurately represent the stance of the US monetary policy although the conventional monetary policy tool loses its information contents (Figs. 1 and 2). Second, the term spread has predictive power for the US economic activity, particularly during the US UMP episode (see, Hännikäinen 2015). In that regard, several studies used the term spread to assess the effects of UMP (see, for example, Chen et al. (2016), Huang (2019), and Olani (2020) for the United States; Feldkircher et al. (2020) for the Euro area; and Koeda (2019) for Japan). We follow these studies and use the term spread as another measure of US UMP in this study.

Overall, we extend the above arguments by stating that if the LSAPs (UMPs) are successful or effective, spreads should fall because of the reduction in risk premiums for private securities and the fall in borrowers' costs of credit (Fig. 2). Considering that the mortgage spread and the term spread have been largely driven by the Fed's asset

\footnotetext{
${ }^{4}$ See Aharon et al. (2021) for the connectedness among the term structure of US interest rates, five traditional safehaven currencies (the CAD, CHF, EURO, JPY, and GBP), and Bitcoin.

5 See Cheng and Chiu (2020) for evidence regarding the counter cycle future of mortgage spread.

${ }^{6}$ See a recent study of Horvath and Rothman (2021) for the macroeconomic effects of US mortgage spread shocks on EMEs.
} 
purchases during the US UMP period, we use them as means to assess whether the US UMP affects the financial markets of advanced economies (AEs) and emerging market economies (EMEs). To quantify the effects on the international financial markets, we estimate a daily structural vector autoregressive (SVAR) model for each US UMP measure (mortgage and term spread) and each of 40 countries (20 EMEs and 20 AEs) from July 2007 to February 2013, covering all three QE periods. The price-based measures (interest rate spreads [the top panel of Fig. 2]) were used instead of asset-based measures (the Fed's asset holdings [the bottom panel of Fig. 2]) because of the following reasons. First, the empirical analysis with asset-based measures may cause the problem of better anticipation of the asset purchase program. However, the spread shocks capture both asset purchase announcements and market expectations, and the analysis with these shocks should avoid this problem (Hesse et al. 2018). Second, the UMP sample is very short compared with the conventional monetary policy sample (Fig. 1). Thus, vector autoregression (VAR) studies, notably with low-frequency measures of US UMP, may generate imprecise estimates. This problem may be alleviated by using high-frequency daily measures of US UMP, such as the interest rate spread. ${ }^{7}$

The present study reveals the following: (1) US spread shocks significantly affect financial markets in EMEs and AEs through the risk-taking channel, suggesting that US UMP drives global risk perceptions and thereby shapes global financial conditions. (2) US mortgage and term spread shocks produce similar financial spillovers into the rest of the world. Nevertheless, the magnitude of the estimated spillovers depends on the type of shocks; mortgage spread shocks relative to term spread shocks have more sizable effects on foreign financial markets. (3) Expectedly, the estimated spillovers from US UMP shocks vary across countries and within country groups.

The remainder of the paper is organized as follows. "Stylized Facts" section documents stylized facts characterizing the role of the Fed's UMP measures in shaping global financial conditions. "Channels of US UMP and Literature Review" section discusses the theoretical channels of US UMP and reviews the literature. "Empirical Analysis" section introduces the empirical model and explains the identification assumptions. "Empirical Results" section reports empirical findings regarding the effects of US UMP on the financial markets of EMEs and AEs. "Robustness" section documents the results of the robustness tests. "Conclusion" section concludes the study.

\section{Stylized facts}

We begin by documenting stylized facts about the stance of US UMP indicators. Figure 2 illustrates the relationships between the Fed's balance sheet holdings of private and Treasury securities (MBS and TS) and US interest rate spreads (term and mortgage spreads). This figure reveals that the relationship between the Fed's MBS holdings and mortgage spread is generally negative and strong, particularly during the QE1 and QE3 periods. In other words, MBS holdings substantially decrease the mortgage spread during these periods. The correlation between the two variables during the QE1 and QE3 periods, when the MBS purchases were heavily used as a UMP instrument, is -0.89 and -0.55 , respectively, which is consistent with the objective of QE1 and QE3.

\footnotetext{
7 The balance sheets of the Fed include relatively low-frequency (weekly) data on the securities (MBS and TS) held outright. In the robustness section, we address the spillovers of asset purchase (MBS or TS) shocks.
} 
However, the relationship between the Fed's TS holdings and term spread is weak and generally positive during all $\mathrm{QE}$ periods.

The link is negative only in the operation twist episode (the correlation between the variables is - 0.35). This result suggests that the Fed's purchases of US Treasury securities are not considerably effective in reducing the term spread (see Blinder (2012)). Based on these facts and consistent with Chudik and Fratzscher (2011), Walentin (2014), Feldkircher et al. (2020), and Chen et al. (2016), our empirical analysis applies interest rate spreads as indicators of US UMP.

What are the international consequences of the Fed's UMP measures depicted in Fig. 2? How do these measures affect financial conditions in emerging and advanced countries? How can we quantify these effects? To answer these questions, we start with Fig. 3, which illustrates the international consequences of the Fed's unconventional measures by depicting the behavior of financial variables of EMEs and AEs during QE periods. The figure shows an observable common trend in EME's and AE's financial variables during these episodes.

More specifically, EMEs and AEs experienced trends of their currencies appreciating against the dollar, falling bond yields and CDS premiums, and rising stock prices during the Fed's QE programs. Figure 3, along with Fig. 2, reveals an important stylized fact about the role of the US monetary policy in shaping the global financial environment. That is, financial conditions in EMEs and AEs are largely driven by US UMP measures.

The mechanism underlying the leading role of US UMP depends on two crucial characteristics of the US monetary policy. First, the Fed's actions immediately change the value of the global currency (dollar exchange rate), which is a crucial global risk factor as it affects the balance sheets of global banks and dollar borrowers (local banks, firms, and corporations) in EMEs and AEs and thereby their activities. ${ }^{8}$ Second, the US monetary policy significantly alters the risk aversion in international financial markets and thus global risk appetite. In sum, the US UMP shapes global financial conditions by altering the value of the US dollar and investors' risk appetites. These characteristics are important determinants of capital flows.

\section{Channels of US UMP and literature review}

The UMP actions taken by the Fed significantly affect financial markets in the US and other countries. Many theoretical channels explain how these effects occur. In theory, these actions influence the US domestic financial markets through some well-known channels, ${ }^{9}$ such as portfolio rebalancing, policy signaling, expectation, scarcity, duration, and market liquidity channels. From another aspect, the Fed's LSPA or QE program and forward guidance also have spillover ${ }^{10}$ effects on international financial markets, which are the primary focus of this paper. The spillover channels of US UMP on international financial markets are known as signaling, portfolio balance, and risk-taking

\footnotetext{
${ }^{8}$ See Avdjiev et al. (2019), Ho et al. (2018), Lee et al. (2017) and Hofmann et al. (2016).

9 See Krishnamurthy and Vissing-Jorgensen (2011), d'Amico et al. (2012) and Wang (2019) for further information on how these channels work.

10 See Kou et al. (2021) for the importance of spillover effects in terms of banks' activities, such as financial technology investment.
} 


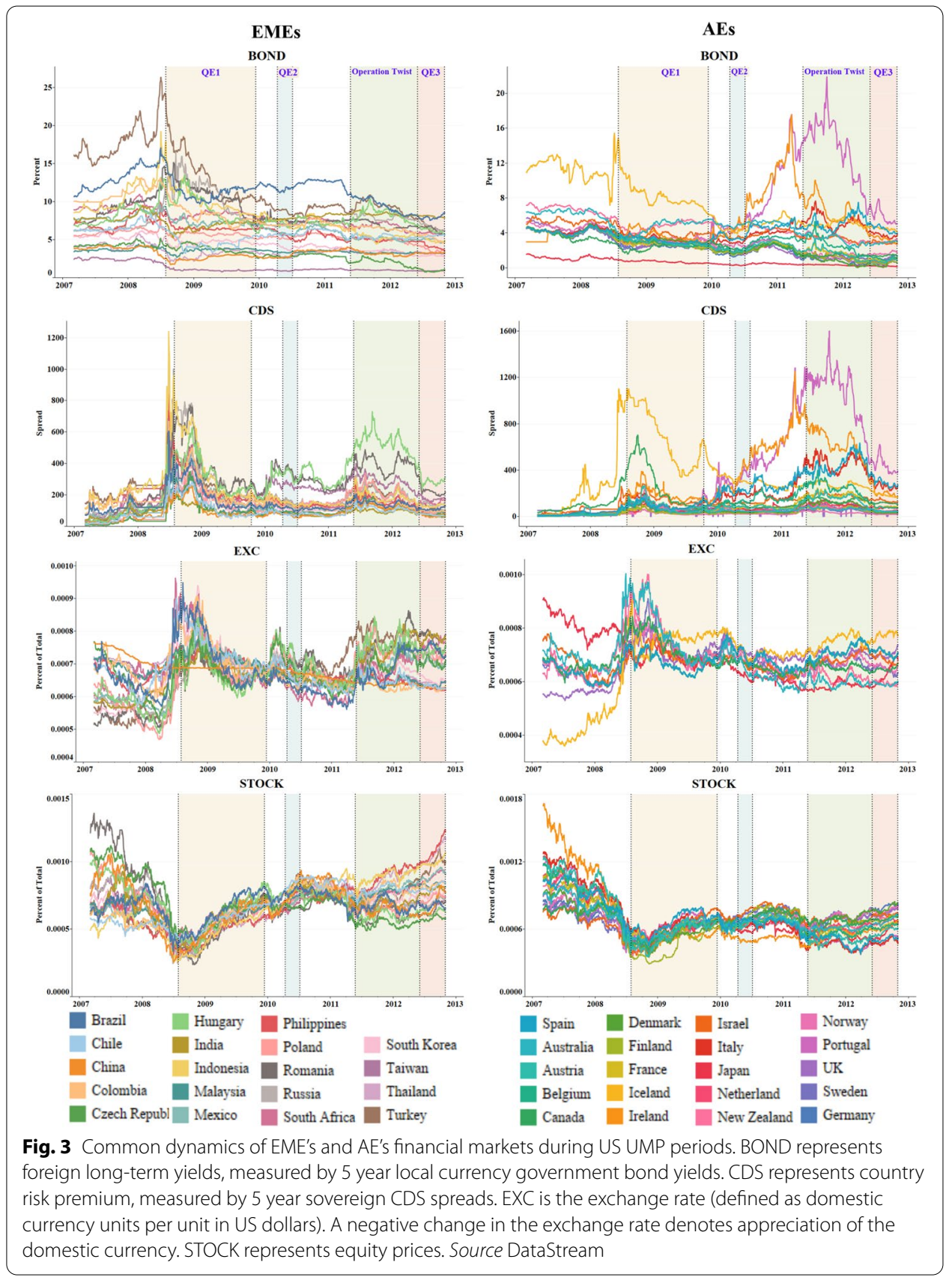

channels. ${ }^{11}$ The signaling channel suggests that the QE announcements and operations induce investors to search for international assets with potentially higher returns, such as government debts of AEs and EMEs, by offering a credible signal regarding the future short-term US interest rate and by decreasing the expectation component of long-term interest rates. The portfolio balance channel posits that international investors alter their portfolio composition from US assets to international assets with higher yields as

${ }^{11}$ See Rey (2016), MacDonald (2017), Bauer and Neely (2014), and Fratzscher, Lo Duca, and Straub (2017) for the international spillover channels of US UMP. 
the LSPAs reduce the asset supply in US markets, raise their prices, and decrease their returns. The risk-taking channel is relatively new and gaining importance, ${ }^{12}$ suggesting that the US UMP is transmitted to the rest of the world by altering the risk-taking behavior of market participants. That is, the LSAP program leads to worldwide spillovers through the shifts in international investors' risk appetites, ${ }^{13}$ driving foreign asset prices by affecting financial intermediary leverage, bank lending, and portfolio inflows into international economies.

Since the start of the Fed's QE program, a growing number of studies empirically investigated the effects of US UMP on financial markets. ${ }^{14}$ Early studies focused on the announcement effects of the QE by employing event study analysis, but some works used structural time series (or regression) analysis to quantify these effects. Gagnon et al. (2011); Krishnamurthy and Vissing-Jorgensen (2011); and Hamilton and Wu (2012) focused on the effect of the LSAPs on domestic financial markets and found that the QE policy has significantly lowered US long-term yields. Many other researchers (e.g., Neely (2015); Bowman et al. (2015); Tillmann (2016); Fratzscher et al. (2017); Aizenman et al. (2016)) examined the international financial spillovers of QE announcements and documented substantial spillovers from US UMP into the rest of the world. ${ }^{15}$

By contrast, recent studies used the Fed's balance sheet holdings of MBS and TS or/ and interest rate spreads as a metric for the QE policy and largely adopted a vector autoregression approach to assess the effects of US UMP. In an early study, Gambacorta et al. (2014) used central bank balance sheets as the UMP instrument and assessed the effects of unconventional monetary policies on domestic real economies by estimating a panel VAR. Other studies adopting similar UMP instruments (e.g., MacDonald (2017); Bhattarai et al. (2021); Dahlhaus et al. (2018); Apostolou and Beirne (2018)) focused on international spillovers. From another aspect, the second strand of this literature used an interest rate spread-such as the term spread, corporate spread, and mortgage spread-as a measure of US UMP. Most of these studies (see, for instance, Baumeistera and Benatib (2013); Liu et al. (2018); Hesse et al. (2018); Feldkircher and Huber (2018); Huang (2019)) documented findings regarding the domestic effects of a spread shock ${ }^{16}$ notably term spread shocks, with only two exceptions (Cheng and Chiu 2020; Walentin 2014), which address a mortgage spread shock. However, the empirical evidence on the international financial spillovers of US spread shocks is very scarce. To the best of our knowledge, only a few studies-Chudik and Fratzscher (2011) and Chen et al.

\footnotetext{
12 (Rey, 2015, 2016), Bruno and Shin (2015), and Bekaert, Hoerova, and Duca (2013) are earlier studies that indicate the importance of the risk-taking channel. Jordà, Schularick, Taylor, and Ward (2019) have recently revealed that the synchronization of international risk taking is growing. They emphasize that this synchronization is mostly dictated by US MP, which is a dominant global risk appetite driver. Miranda-Agrippino and Rey (2020) also suggest that US MP influences risk premiums, leverage, and credit growth in the rest of the world. Moreover, Ward (2018) reveals that the international risk-taking channel accounts for around 30\% of US monetary policy spillovers. Bernanke (2017) discusses the importance of these studies and the risk-taking channel.

13 Risk appetite is market participants' willingness to bear risk while expecting to generate potential profit. Gai and Vause (2004) offer detailed information on concept and measurement of risk appetite. In addition these measures, machine learning methods are also used to measure market sentiments (see Kou et al. (2019)).

14 Bhattarai and Neely (2016) and Cecioni et al. (2011) offer a review of literature on the estimated effects of US UMP on financial markets.

${ }^{15}$ Many countries experience currency appreciation, rising stock prices, and declining sovereign debt yields during expansionary periods of US UMP (see Figs. 1,2 and 3). However, the process violently reverses during tapering or tightening periods of US UMP (see Aizenman et al. (2016); Eichengreen and Gupta (2015); and Tule et al. (2019)).

16 Koeda (2019), on the other hand, focuses on the BOJ's QE policy and examine the domestic effects of term spread shocks.
} 
(2016) - examined the spillovers from US spread shocks. ${ }^{17}$ The former focused on the spillovers from a US TED spread shock, whereas the latter addressed the spillovers from US corporate spread and term spread shocks.

Our approach to US UMP spillover effects on the rest of the world is methodologically similar to that of Chudik and Fratzscher (2011) and Chen et al. (2016) but differs in two important ways. First, our US UMP instruments are mortgage and term spreads, which are different from theirs. Second, we compare the effects of UMP by using mortgage and term spreads based on data from 20 EMEs and 20 AEs. In that regard, our study complements their analysis.

The present study is also related to other strands of the literature focusing on the effects of the central bank balance sheet. A consensus has been growing in the recent literature that the Fed's purchases of different types of assets have different effects on financial markets and macroeconomic performance (e.g., MacDonald (2017); Chen et al. (2016); Dai et al. (2013)). This consensus implies that the sign and magnitude of international spillovers of US UMP may substantially vary depending on which type of assets the Fed purchases (MBS vs. TS). However, the literature had been largely silent on these potential differences in the international spillover effects. We address this issue directly by considering asset purchase shocks and indirectly by comparing the effects of mortgage and term spread shocks. Finally, our study complements a relatively new branch of the literature emphasized above, which focuses on the role of the risk-taking channel in international spillovers (see Rey (2015); Bruno and Shin (2015); Miranda-Agrippino and Rey (2020); Lee et al. (2017); Ward (2018); Jordà et al. (2019)). Consistent with this literature, we found that the risk-taking channel plays an important role in transmitting US UMP to international financial markets.

\section{Empirical analysis}

\section{Data and country coverage}

We use daily data to investigate spillovers from US UMP to EMEs and AEs. The data span from July 2007 to February 2013, beginning with the onset of the global financial crisis and ending before the first discussions of QE program tapering. Figure 2 shows the Fed conducted UMP measures during our sample period, which captures all three QE periods. All data are obtained from DataStream. Our country sample includes 20 EMEs and $20 \mathrm{AEs}$, totaling 40 countries. The country choice is based on data availability and active financial markets. Our data set is larger than that used in a typical study in the literature investigating US UMP spillover effects. Table 1 shows the list of emerging and advanced countries.

The dataset includes variables within the two blocks, namely, Foreign (F) and Home $(\mathrm{H})$, of the model, with F representing the US economy (called also US block) and $\mathrm{H}$ representing an emerging (advanced) economy (called also EME (AE) block). The choice of variables for the US and EME (AE) blocks is mainly guided by the international transmission mechanism of US UMP proposed by the risk-taking channel. According to proponents of the risk-taking channel, US UMP encourages investors to take more risks and reshape their portfolios. This change in investors' risk-taking behavior induces capital

${ }^{17}$ In a recent work, Feldkircher et al. (2020) use the euro area term spread as a QE measure and report the international effects of a reduction in Euro area term spreads. 
Table 1 Country / region sample

\begin{tabular}{llll}
\hline EMEs & \multicolumn{3}{l}{ AEs } \\
\hline Brazil [BRA] & Philippines [PHL] & Australia [AUS] & Israel [ISR] \\
Chile $[\mathrm{CHL}]$ & Poland [POL] & Austria [AUS] & Italy [ITA] \\
China [CHI] & Romania [ROM] & Belgium [BEL] & Japan [JAP] \\
Colombia [COL] & Russia [RUS] & Canada [CAN] & Netherlands [NET] \\
Czech Republic [CZR] & South Africa [ZAF] & Denmark [DEN] & New Zealand [NZE] \\
Hungary [HUN] & South Korea [SKO] & Finland [FiN] & Norway [NOR] \\
India [IND] & Taiwan [TAI] & France [FRA] & Portugal [POR] \\
Indonesia [IDO] & Thailand [THA] & Germany [GER] & Spain [SPA] \\
Malaysia [MAL] & Turkey [TUR] & Iceland [ICE] & Sweden [SWD] \\
Mexico [MEX] & Venezuela [VEN] & Ireland [IRE] & United Kingdom [UK] \\
\hline
\end{tabular}

inflows to the rest of the world and thus transmits US UMP measures to other countries' financial markets. Portfolio inflows ${ }^{18}$ driven by the US monetary policy strongly influence stock prices, bond yields, exchange rates, and country risk premiums. To examine these potential effects of US UMP, we use a six-variable SVAR model, with two US variables - an indicator of US UMP and a measure of risk appetite-and four EME (AE) variables, namely, a measure of long-term interest rate, an index of equity prices, a nominal bilateral exchange rate, and a measure of country risk premium. Figure 4 shows a schematic illustration of our model.

The US variables consist of two US UMP indicators and the VIX index, used as an aggregate proxy for global risk appetite (see ECB (June 2007) for alternative indicators of risk appetite). In this study, in line with the recent literature, the stance of US UMP is captured by two interest rate spreads: the US mortgage spread between the 30 year mortgage and 10 year Treasury bond rates and the US term spread between 30 and 10 year Treasury yields (Fig. 2).

Additionally, the risk-taking channel of US UMP is captured by the VIX index. The existing literature offered ample evidence on how the US monetary policy (conventional or unconventional) influences the VIX. The literature revealed that an expansionary (contractionary) US monetary policy decreases (increases) the VIX index (Bekaert et al. 2013; Rey 2016; Anaya et al. 2017; Gambacorta et al. 2014; Bruno and Shin 2015; Tillmann 2016; Dedola et al. 2017). Accordingly, the US monetary policy raises market participants' risk appetite, triggering portfolio inflows to the rest of the world and leading to increases in foreign asset (equity and bond) prices and appreciation in domestic currencies against the US dollar. Consistent with this literature, we expect the VIX index to fall in response to a reduction in the mortgage or term spread (expansionary monetary policy). However, as emphasized by Anaya et al. (2017), UMP measures may heighten volatility by raising uncertainty about the monetary policy's future path, which is theoretically possible. Consequently, the theoretical links between UMP and the VIX index have not yet been well documented in the literature.

\footnotetext{
18 These inflows lead to a build-up of vulnerabilities in the rest of the world's financial system, forcing the authorizes to implement macro-prudential policies (Ouyang and Guo 2019). See also Chao, Kou, Peng, and Alsaadi (2019) for how such polices can be used to prevent abnormal cross-border money transferring accompanied by trade background.
} 


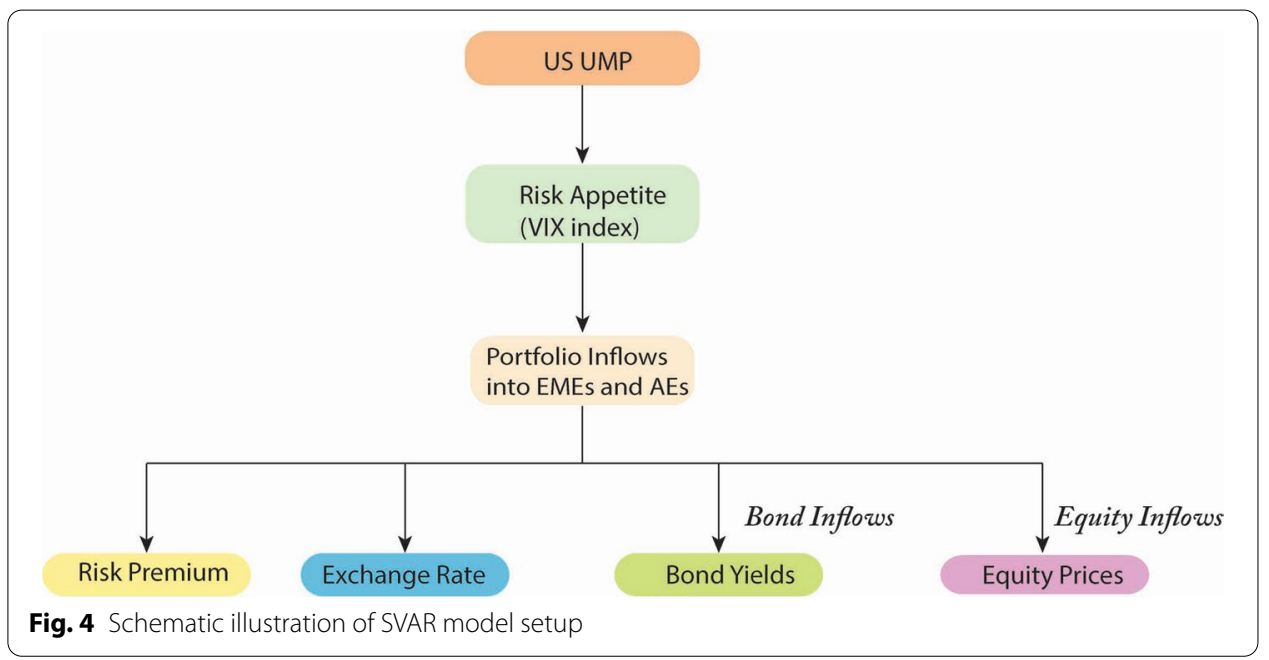

On the basis of the aforementioned majority of literature that documented strong co-movement between the VIX index and measures of the US monetary policy stance, we theoretically expect that an expansionary monetary policy in the US decreases risk aversion (the VIX index), that is, increases risk appetite and lessens uncertainty in the financial markets, particularly in the stock markets. The existence of a negative relation between the US monetary policy and the VIX leads capital flows from the US to the rest of the world.

The EME (AE) variables comprise four country-specific financial variables: (i) the long-term interest rate (represented by 5 year government bond yields ${ }^{19}$ ), (ii) the equity prices, (iii) the bilateral exchange rate against the US dollar, ${ }^{20}$ and (iv) the country risk premium (measured by the 5 year sovereign CDS spread).

\section{SVAR model}

VAR-type modeling is a widely used approach to examine the international spillover effects of US conventional monetary policy (see, e.g., Canova (2005), Maćkowiak (2007), and Carrillo et al. (2020), among others) and UMP (see, e.g., Bowman et al. (2015), Tillmann (2016), and Bhattarai et al. (2021), among others). This approach has several important advantages. First, the VAR-type modeling enables us to model the contemporaneous and lagged dynamics between US UMP and foreign financial markets. Second, we can divide the VAR system into blocks, for example, domestic and foreign, and determine the block structure of the system by imposing restrictions, such as block exogeneity restrictions, on the interactions across blocks. Thus, the VAR-type approach allows us to adopt a partial identification strategy. Third, with this modeling strategy, we can analyze the spillover effects of US spread and asset purchase shocks on AEs and EMEs.

To analyze international financial spillovers from US UMP, we apply an SVAR model with two blocks (foreign [US] and home [AE or EME]) for

\footnotetext{
19 The long-term interest rate can also be measured by 10- year government bond yields. However, the historical data for this variable is not readily available for all countries in our sample.

20 The exchange rate is defined as domestic currency units per unit in US dollars. A negative change in the exchange rate denotes appreciation of the domestic currency.
} 
$\Delta x_{t}=\left\lceil\Delta \text { spread }_{i t}^{U S}, \Delta v i x_{t}^{U S}, \Delta r_{i t}, \Delta e_{i t}, \Delta s_{i t}, \Delta \rho_{i t}\right\rceil^{\prime}$, where $\Delta$ spread $_{i t}^{U S}$ is the first difference of a US (mortgage or term) spread-subscript $i$ represents each of two US UMP indicators; $\Delta v i x_{t}^{U S}$ is the first difference of the (log) VIX index; $\Delta r_{i t}$ is the first difference of 5 year government bond yields; $\Delta e_{i t}$ is the first difference of the (log) equity prices; $\Delta s_{i t}$ is the first difference of the (log) exchange rate; $\Delta \rho_{i t}$ is the first difference of the (log) 5 year sovereign CDS spread-subscript $i$ represents each country (AE or EME) in the sample (Table 1). The structural VAR system is as follows:

$$
B(L) \Delta x_{t}=\varepsilon_{t},
$$

where $B(L)=B_{0}-B_{1} L-B_{2} L^{2}-\cdots-B_{p} L^{p}$ is a matrix polynomial in the lag operator L. $B_{0}$ denotes the $6 \times 6$ contemporaneous coefficient matrix. $\varepsilon_{t}$ is the vector of structural shocks with a zero mean and a diagonal covariance matrix, $E\left(\varepsilon_{t} \varepsilon^{\prime}{ }_{t}\right)=\Lambda$.

To discuss the interactions across the blocks and determine the block structure of Eq. (1), $\Delta x_{t}$ is partitioned on the basis of the origin of variables such that $\Delta x_{t}=\left\lceil\Delta x_{t}^{F}, \Delta x_{i t}^{H}\right\rceil^{\prime}$, where $\Delta x_{t}^{F}=\left\lceil\Delta \text { spread }_{i t}^{U S}, \Delta v i x_{t}^{U S}\right\rceil^{\prime}$ is a vector of foreign (US) variables and $\Delta x_{i t}^{H}=\left\lceil\Delta r_{i t}, \Delta e_{i t}, \Delta s_{i t}, \Delta \rho_{i t}\right\rceil^{\prime}$ is a vector of home (AE or EME) variablessubscript $i$ represents each country (AE or EME) in the sample. The block structure is then represented by the partitioned form of the $B$ matrix:

$$
B_{i}=\left[\begin{array}{cc}
B_{i}^{F F} & 0 \\
B_{i}^{H F} & B_{i}^{H H}
\end{array}\right], \quad i=0,1,2 \ldots, p
$$

We treat each country in the sample as a small-open economy, ${ }^{21}$ which shapes the block structure of the model by imposing the block exogeneity restriction on the $B_{i}$ matrix, identifying two blocks. The zero block- $B_{i}^{F H}$-represents the small-open economy assumption, suggesting no feedback from the home economy (AE or EME) to the foreign economy (US), either contemporaneously or with lags. This block structureformed by the block exogeneity restriction ${ }^{22}$-is a standard in the open-economy SVAR literature (see, for instance, Canova (2005) and Maćkowiak (2007)) on the international effects of US monetary policy shocks since the pioneering work of Cushman and Zha (1997). The reason is that introducing the small-open economy (e.g., block exogeneity) assumption to the model brings three significant advantages. First, the exogeneity assumption decreases the number of parameters to estimate and hence enables us to include a larger set of foreign and domestic variables into the model. Second, this assumption helps avoid the spurious spillovers by allowing only one-way interaction across blocks, that is, this assumption does not permit feedback from a small domestic economy (e.g., a typical EME [or AE]) to a large foreign economy (US). Last, the block

\footnotetext{
${ }^{21}$ It can be argued that this assumption has limitations for large advanced economies, especially for Japan and strong European countries such as Germany, France and UK. Each of these countries may exert significant effects on international financial markets and US economy. Thus, the SVAR set-up that allows feedback between home economy (e.g., Germany) and foreign economy (US) may be more appropriate for these countries. In this sense, we re-design the block structure of the model and re-estimate it for each of these large advanced countries. The results remain unchanged. They are available upon request.

22 In the macroeconometric modeling, the block exogeneity assumption comes from fundamental small-open economy aspect in the international macroeconomic theory. Thus, for a small-open economy, a VAR-type modeling without block-exogeneity assumption violates the theory and is not economically meaningful. In addition, Zha (1999) clearly shows this type modeling that ignores the exogeneity assumption may generate imprecise estimates and result in misleading conclusions. Thus, the block-exogeneity assumption is crucial for economically and statistically significant findings while examining the effects of external shocks on small open economies.
} 
exogeneity assumption allows better identification of structural parameters (see, Buckle et al. (2007)).

\section{Identification}

The short-run zero restrictions are used to recover the structural parameters. To uncover the underlying structural shocks, the reduced-form VAR corresponding to the structural model is initially estimated as follows:

$$
C(L) \Delta x_{t}=u_{t},
$$

where $C(L)=\left(B_{0}\right)^{-1} B(L)$ and $u_{t}=\left(B_{0}\right)^{-1} \varepsilon_{t}$ is a vector of reduced-form residuals. Then, we impose restrictions on contemporaneous coefficients matrix, $B_{0}$, to recover the structural shocks from the estimated residuals. The block exogeneity restriction results in a partial system, thereby allowing us to adopt a partial identification strategy. Hence, our SVAR system with the block exogeneity enables us to focus only on the structural interpretation of the US block. In this sense, we impose zero restrictions only on this block-technically, on the submatrix of $B_{0}, B_{0}^{F F}$,-to identify two US shocks, namely, spread and VIX shocks. Then, we leave the elements of $B_{0}^{H F}$ and $B_{0}^{H H}$ unrestricted. ${ }^{23}$

The US shocks are identified by placing a zero restriction on $B_{0}^{F F}$. We assume that US UMP instruments (spreads) affect the VIX contemporaneously. However, the VIX has no contemporaneous effect on US UMP. This assumption, which is widely used in the SVAR-based literature (see, e.g., Chen et al. (2016), Bruno and Shin (2015), and Bekaert et al. (2013)), imposes a contemporaneous zero restriction on the US block $\left(b_{12}=0\right)$. Overall, the following matrix, $B_{0}$, summarizes our identification strategy:

$$
\left(\begin{array}{l}
u_{i t}^{\Delta s p r e a d} \\
u_{t}^{\Delta V I X} \\
u_{i t}^{\Delta r} \\
u_{i t}^{\Delta e} \\
u_{i t}^{\Delta s} \\
u_{i t}^{\Delta \rho}
\end{array}\right)=\left(\begin{array}{cc|cccc}
1 & 0 & 0 & 0 & 0 & 0 \\
b_{21} & 1 & 0 & 0 & 0 & 0 \\
\hline b_{31} & b_{32} & 1 & b_{34} & b_{35} & b_{36} \\
b_{41} & b_{42} & b_{43} & 1 & b_{45} & b_{46} \\
b_{51} & b_{52} & b_{53} & b_{54} & 1 & b_{56} \\
b_{61} & b_{62} & b_{63} & b_{64} & b_{65} & 1
\end{array}\right)\left(\begin{array}{l}
\varepsilon_{i t}^{\text {spread shock }} \\
\varepsilon_{t}^{V I X ~ s h o c k} \\
\varepsilon_{i t}^{\Delta r} \\
\varepsilon_{i t}^{\Delta e} \\
\varepsilon_{i t}^{\Delta s} \\
\varepsilon_{i t}^{\Delta \rho}
\end{array}\right)
$$

The structural model (Eq. (1)) is estimated separately for each of 40 countries (20 EMEs and $20 \mathrm{AEs}$ ) and the QE measures. Figure 5 depicts a graphical view of our estimation procedure that illustrates how to obtain the structural parameters and impulse response functions with the posterior probability bands. The estimation procedure is based on a Bayesian Markov Chain Monte Carlo (MCMC) simulation method. To acquire the parameter estimates and construct the posterior probability bands of impulse response functions, we apply the following steps (Fig. 5). First, the reduced-form version of the model (Eq. (3)) is estimated using the SUR technique with one lag based on the Schwartz Bayesian criteria to obtain the initial estimates for the Gibbs sampler. Second, the point

${ }^{23}$ Alternatively, we also impose zero restrictions on the home block. In this regard, $B_{0}^{H H}$ is also restricted to be lower triangular. Though this results in a just-identified model, it does not change our findings. The corresponding results are available upon request. 


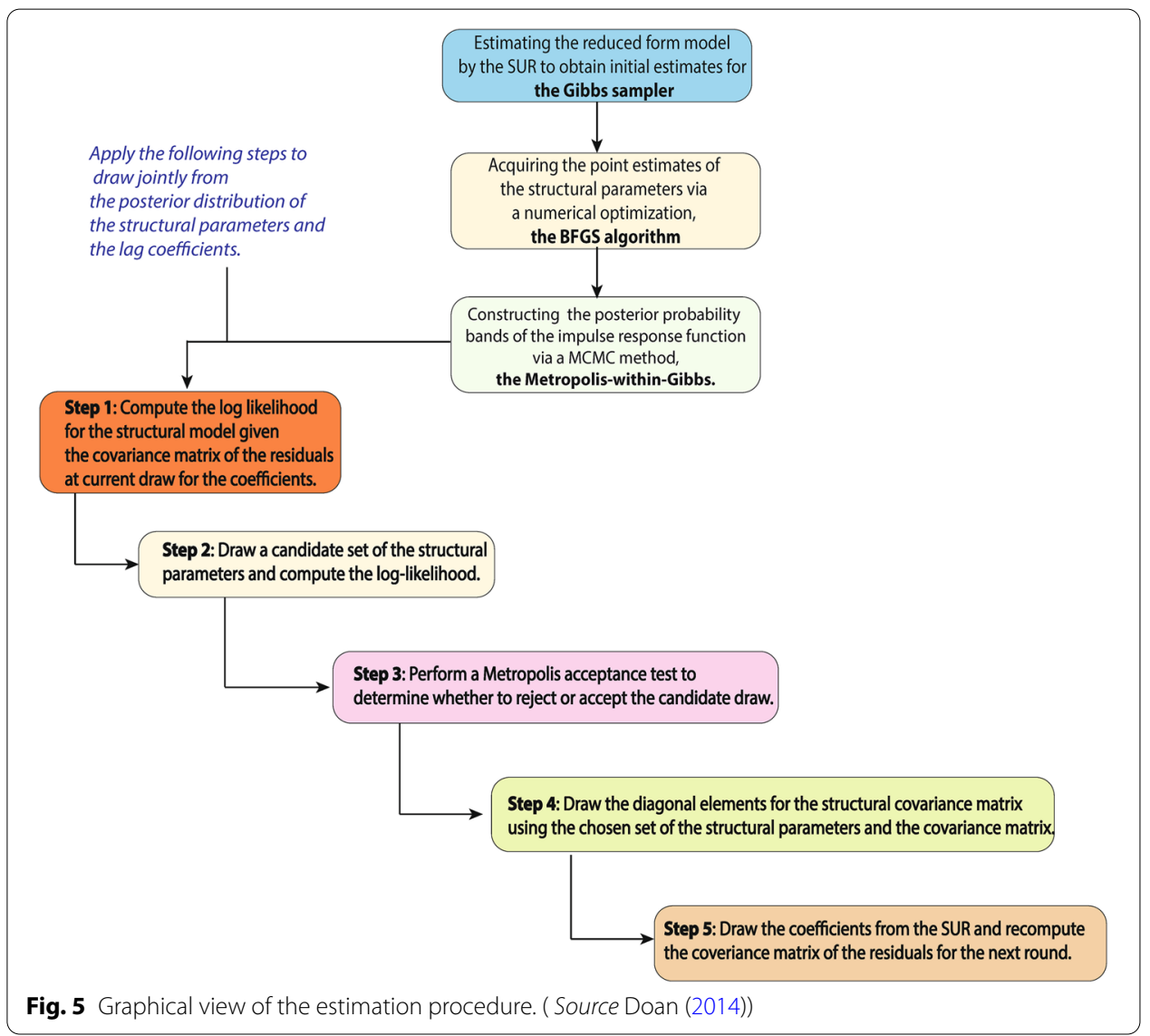

estimates of the structural parameters $\left(B_{0}\right)$ are acquired on the basis of their marginal posterior distribution. ${ }^{24}$ Then, the probability bands for impulse response functions are constructed by drawing jointly from the posterior distribution of $B_{0}$ and the lag coefficients $B(L)$. To do this, we use the Metropolis-within-Gibbs sampling algorithm, which is a more advanced form of MCMC methods (see Doan (2015) for more details). By applying this algorithm with the steps illustrated in Fig. 5, we compute the countryspecific impulse response functions along with the $68 \%$ and $95 \%$ posterior probability bands ${ }^{25}$ and report them in Appendix Figs. 13 and 14.

\section{Empirical results}

In this section, we first present the descriptive statistics of our data (Table 2), next document the point estimates of the SVAR parameters (Table 3), and then report the aggregated impulse responses (Fig. 6a, b). Table 2 shows the statistics of the variables used in our estimation procedure. When we compare the standard deviation of two indicators (mortgage and term spreads) of UMP, the volatility of mortgage spread is

\footnotetext{
${ }^{24}$ The point estimates are obtained by finding the posterior modes via a numerical optimization. The maximization of the log of the marginal posterior distribution is conducted by using the Broyden-Fletcher-Goldfarb-Shanno (the BFGS) algorithm. The prior degrees of freedom are set to ensure an integrable posterior distribution (Prior DF $=3.5$ ).

25 We discard an initial 2,000 burn-in draws and consider 10,000 accepted draws in which the scale of the proposal density is chosen to give a reasonable Metropolis acceptance rate (around 40\%). Based on these accepted draws, we compute the median responses along with the $68 \%$ and $95 \%$ posterior probability bands.
} 
Table 2 Descriptive statistics of data

\begin{tabular}{llrrrrr}
\hline F/H & Variables & \multicolumn{1}{c}{ Mean } & Median & Maximum & Minimum & SD \\
\hline US & $\Delta$ sprea $_{t}^{\text {Mortgage }}$ & 0.00025 & 0.00000 & 0.59100 & -0.45100 & 0.08624 \\
& $\Delta$ sprea $_{t}^{\text {Term }}$ & 0.00075 & 0.00000 & 0.25000 & -0.14000 & 0.02577 \\
& $\Delta$ vix $_{t}^{U S}$ & -0.00003 & -0.00390 & 0.40547 & -0.35059 & 0.07143 \\
\multirow{2}{*}{ Typical EM } & $\Delta r_{t}$ & -0.00128 & 0.00000 & 1.93055 & -1.77595 & 0.18234 \\
& $\Delta e_{t}$ & 0.00017 & 0.00011 & 0.10418 & -0.10988 & 0.01563 \\
& $\Delta s_{t}$ & 0.00009 & -0.00006 & 0.07085 & -0.04338 & 0.00783 \\
& $\Delta \rho_{t}$ & 0.00085 & 0.00000 & 0.50794 & -0.36554 & 0.04544 \\
\multirow{2}{*}{ Typical AE } & $\Delta r_{t}$ & -0.00202 & -0.00145 & 0.74495 & -0.69790 & 0.08910 \\
& $\Delta e_{t}$ & -0.00034 & 0.00005 & 0.09607 & -0.14354 & 0.01650 \\
& $\Delta s_{t}$ & 0.00002 & -0.00004 & 0.04786 & -0.05293 & 0.00794 \\
& $\Delta \rho_{t}$ & 0.00172 & 0.00000 & 0.80455 & -0.89786 & 0.06722 \\
\hline
\end{tabular}

Typical EM (AE) represents the average of the descriptive statistics of $20 \mathrm{EMs}$ (AEs)

3.35 times higher than that of term spreads. Consistent with this, as shown in Fig. 6a, b and Appendix Figs. 13 and 14, the mortgage spread shocks exert statistically more significant effects on the financial variables of AEs and EMEs compared with those of the term spread shocks, which is one of our main findings. Table 2 also shows that the volatility (Std.dev) of bonds in a typical EM is 2.25 times higher than that of AE, whereas the volatility of CDS in a typical AE is 1.48 times higher than that of EM.

A striking similarity is observed between the volatility of exchange rate and stock prices in the AEs and EMEs. After analyzing the descriptive statistics, we look at the estimates of the structural parameters and the responses of foreign financial variables to US spread shocks. In this sense, we report two sets of results. The first set denotes financial spillovers from a US mortgage spread shock, whereas the second one shows spillovers from a US term spread shock. In this section, subsequently, we first discuss the estimated SVAR parameters in "Structural parameter estimates" section. Next, we assess the effects of US spread shocks on typical financial markets of EME and AE by aggregating impulse responses into two country groups (EME and AE) in "How do US spread shocks affect financial markets in a typical EME and AE?" section. To reveal how these effects vary across countries and within country groups, in "Do these effects vary across countries and within country groups (EME and AE)?" section, we use a world map and box plots, constructed using the estimated immediate responses of each country's financial markets to the US spread shocks.

\section{Structural parameter estimates}

Table 3 presents the estimated structural parameters, including only those measuring the contemporaneous effect of US shocks because of our focus. This table provides some preliminary findings. First, US mortgage and term spreads have a negative contemporaneous effect on the VIX index, with the former having the greater effect (b21 $=-0.27$ ). This effect is highly statistically significant for both US spreads, with p-values 0.0000 and 0.0081 , respectively. The result suggests that US expansionary $\mathrm{UMP}$, that is, QE policy, reducing the interest rate spreads causes a significant decline 
Table 3 The point estimates of the SVAR parameters

\begin{tabular}{|c|c|c|c|c|c|c|}
\hline \multirow{3}{*}{$\begin{array}{l}\text { Estimated } \\
\text { structural } \\
\text { parameters }\end{array}$} & \multicolumn{6}{|c|}{ Types of US spread shocks } \\
\hline & \multicolumn{3}{|c|}{ Mortgagespread } & \multicolumn{3}{|c|}{ Term spread } \\
\hline & US & Typical EME & Typical AE & US & Typical EME & Typical AE \\
\hline b21 & -0.2745 & & & -0.1952 & & \\
\hline b31 & & -0.0101 & 0.1029 & & 0.0433 & 0.2602 \\
\hline b32 & & -0.0407 & 0.0760 & & -0.0470 & 0.1054 \\
\hline b41 & & 0.0119 & 0.0140 & & 0.0131 & -0.0067 \\
\hline b42 & & 0.0477 & 0.0756 & & 0.0518 & 0.0805 \\
\hline b51 & & -0.0046 & -0.0020 & & 0.0034 & 0.0116 \\
\hline b52 & & -0.0163 & -0.0153 & & -0.0180 & -0.0163 \\
\hline b61 & & -0.0333 & -0.0477 & & -0.0189 & 0.0024 \\
\hline b62 & & -0.1331 & -0.0748 & & -0.1450 & -0.0900 \\
\hline
\end{tabular}

The point estimates of the contemporaneous coefficients matrix, $\mathrm{B}_{0}$, are obtained by using the Broyden-Fletcher-GoldfarbShanno (the BFGS) algorithm. Only the estimated structural parameters measuring the impact of US shocks (spread and VIX) are reported because this study specifically analyzes the influence of such shocks on the global risk appetite and foreign financial markets. The parameters for a typical EME (or AE) are obtained by taking a simple arithmetic average of the estimated parameters of 20 EMEs [or $20 \mathrm{AEs}$ ] (see Appendix Table 4 for country-level estimates). The average parameters represent the results of a typical EME (or AE)

in the VIX index. This finding is broadly consistent with a growing body of the literature on the risk-taking channel of US monetary policy (see, for example, Bekaert et al. (2013), Rey (2016), Anaya et al. (2017), Gambacorta et al. (2014), Bruno and Shin (2015); and among others)). Second, our SVAR model provides theoretically consistent estimates for a typical EME and AE, which are largely in line with the existing empirical literature, particularly for the former (see, Bhattarai and Neely (2016) for the literature review).

Specifically, US expansionary UMP reducing US spreads (or a negative VIX shock) decreases country risk premium, exchange and interest rates while increasing stock prices in a typical EME. Moreover, the country-level estimates of the SVAR parameters with $p$-values also provide striking preliminary findings (Appendix Table 4). The estimated parameters related to the country risk premium, b61 and b62, are highly statistically significant in nearly all EM countries, particularly when the mortgage spread is considered an indicator of US UMP. This result reveals that US UMP that condenses the mortgage spread has an economically and statistically significant effect on EM sovereign risk premiums. In sum, given the highly statistically significant parameters related to the VIX and country-level CDS spreads, that is, b21 and b61-b62, our results suggest that the international risk-taking channel of US UMP is at work, specifically in the transmission of US UMP to EMEs (see, for example, Jordà et al. 2019; Kalemli-Özcan, 2019).

\section{How do US spread shocks affect financial markets in a typical EME and AE?}

Appendix Figs. 13 and 14 show the country-level impulse responses along with the 68\% and $95 \%$ posterior probability bands. These figures reveal that a consistent pattern exists in the responses to US UMP shocks within each country group (EME and AE), with different magnitudes of median responses. Thus, we aggregate the impulse responses with error bands into two country groups (EME [20 countries] and AE [20 countries]) by 


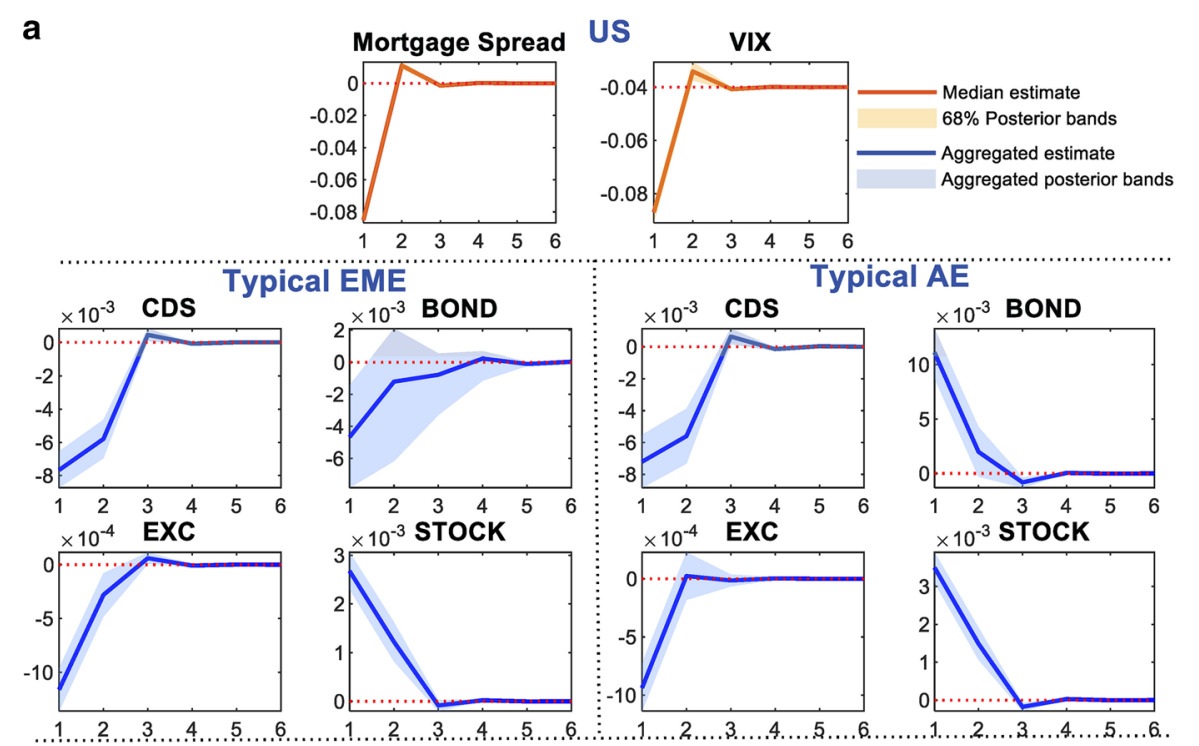

b

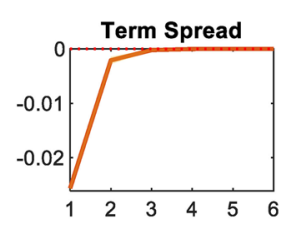

US
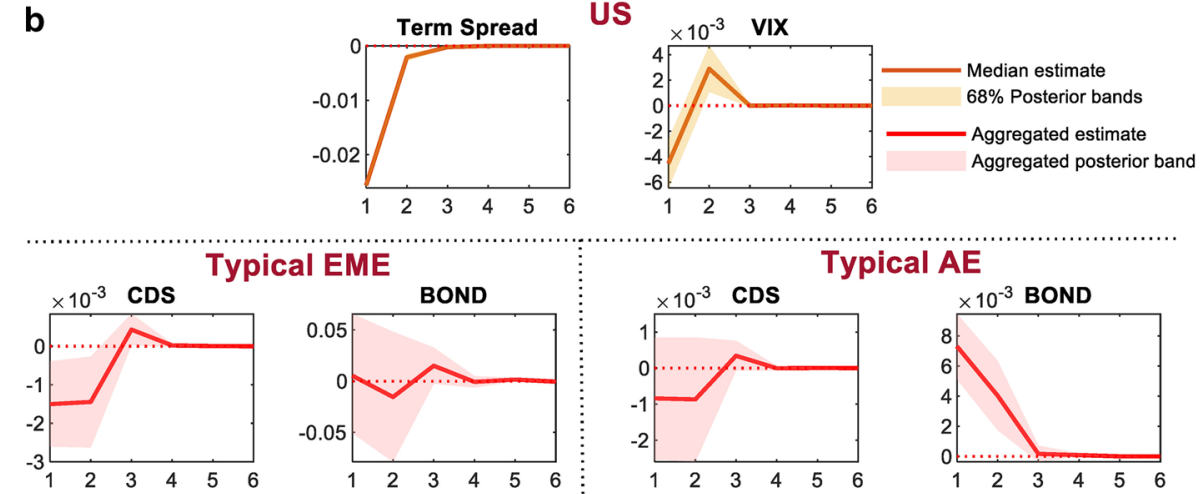

Typical EME
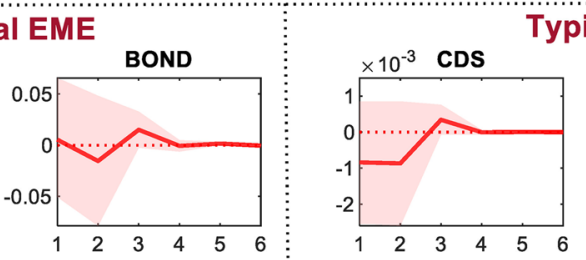

ypical AE
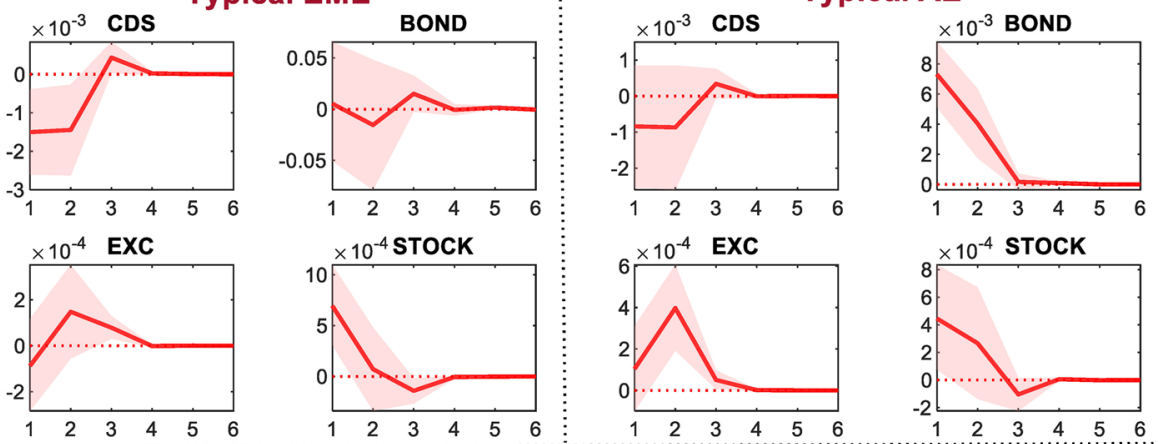

Fig. 6 Responses to US UMP indicators. a Responses of typical foreign financial markets and global risk appetite to a US mortgage spread shock. Notes: The upper panel shows the country-level (US) impulse responses to US mortgage spread shocks along with the $68 \%$ posterior probability bands. The lower panels indicate the average responses (Typical EME and AE) to such shocks. The average impulse response functions are calculated as a simple arithmetic average of the country-specific impulse response functions of 20 EMEs and 20 AEs reported in Appendix Fig. 13 (EMEs) and 14 (AEs). b Responses of typical foreign financial markets and global risk appetite to a US term spread shock. Notes: The upper panel shows the country-level (US) impulse responses to US term spread shocks along with the $68 \%$ posterior probability bands. The lower panels indicate the average responses (Typical EME and AE) to such shocks. The average impulse response functions are calculated as a simple arithmetic average of the country-specific impulse response functions of 20 EMEs and 20 AEs reported in Appendix Fig. 13 (EMEs) and 14 (AEs)

taking a simple arithmetic average of the country-level impulse response functions of 20 EMEs and 20 AEs. Additionally, we refer to these aggregated responses as results for a typical EME and AE. The lower panels of Fig. 6 show the responses of a typical EME and AE to shocks to the US UMP indicators, US mortgage and term spreads. 
Figure 6 presents the responses of global risk appetite (measured by the VIX index) and typical foreign financial markets to US UMP. As shown in the upper panel of Fig. 6a, a shock to the mortgage spread decreases the VIX index, implying that US UMP reducing mortgage spread increases investors' risk appetites. This finding is consistent with Borio and Zhu (2012) who argued the risk-taking channel of monetary policies. They stated that a low interest rate increases the willingness of market participants to take on risk exposures, thereby influencing financial conditions. In this regard, Bekaert et al. (2013) provided evidence that a loosening of monetary policy reduces the VIX index. From another aspect, the mortgage spread shock, as shown in lower panels of Fig. 6a, significantly affects international financial markets. Accordingly, reducing the US mortgage spread strengthens domestic currencies, decreases country risk premiums, and raises stock prices in a typical EME and AE. The estimated effects on foreign bond markets vary widely among EMEs and AEs: US UMP lowering mortgage spread decreases (increases) long-term bond yields in a typical EME (AE). The effect is statistically (in) significant for a typical AE's (EM's) yields. Moreover, the narrow confidence bands of the aggregated impulse responses suggest that a small cross-country dispersion exists in the confidence bands within each country group. However, the wide confidence bands of these aggregated responses (e.g., the response of the typical EME's bond yield) imply a large dispersion in the confidence bands across countries: some EM countries (e.g., China, Czech Republic, Romania, and Thailand) have relatively wide confidence bands, whereas others (e.g., Colombia, Mexico, Poland, and Russia) have narrow bands. Thus, the statistical significance of the effects of a US mortgage spread shock on EMEs' bond market may vary across emerging countries (see Appendix Figs. 13 and 14 for the country-level impulse responses).

We observe largely similar effects in the case of a shock to the term spread (see Appendix Figs. 13 and 14 for the country-level responses to a US term spread shock). The term spread shock, shown in the upper panel of Fig. 6b, also reduces the VIX index, suggesting that the QE policy that reduces the term spread alters the risk-taking behavior of market participants and encourages them to take more risk in shaping their portfolios. The term spread shock also induces similar international financial spillovers. In response to a US term spread shock, in a typical EME, CDS spreads and long-term bond yields decrease, domestic currencies strengthen against the US dollar, and stock prices increase. Correspondingly, in a typical AE, country risk premiums decrease, and equity prices rise. The estimated effects on a typical AE's yields are positive as in the case of the mortgage spread. However, AE currencies respond differently to US UMP lowering the term spread; these currencies typically depreciate in response to the term spread shock.

Overall, our estimated financial spillovers are largely consistent with the stylized facts (documented in Sect. 2) and the findings in the literature on the international transmission of US UMP. ${ }^{26}$ Here, we want to emphasize two important patterns that emerge from these results. First, the two US UMP instruments-mortgage and term spreadshave similar effects on foreign (international) financial markets. However, the mortgage spread shock exerts stronger and more significant effects on international financial

${ }^{26}$ See Bhattarai and Neely (2016) for a comparison of the results. 
markets than the term spread shock. This finding suggests that the Fed's QE policy of reducing the mortgage spread has larger international financial spillovers (this pattern can also be observed from Appendix Figs. 13 and 14). This result indirectly implies that the extent of international financial spillovers from the US to the rest of the world depends on the type of assets the Fed purchases. Second, US UMP shocks-mortgage (or term) spread shocks-significantly decrease the VIX index. On the basis of these results, we argue that US UMP influences foreign financial markets through its effect on the VIX index. To elucidate our argument, we also report the effects of a negative shock to the VIX index on the variables in Fig. 7. Figure 7 shows that a negative VIX shock exerts similar effects on international financial markets, ${ }^{27}$ suggesting that the effects of US UMP on foreign financial markets work through risk appetites (the VIX index).

\section{Do these effects vary across countries and within country groups (EME and AE)?}

Figure 8 shows financial spillovers from US UMP, US mortgage spreads, into the rest of the world at the country level, indicating that financial spillovers are strong and vary substantially across countries. For long-term interest rates, the sign of spillover effects substantially varies across countries. AEs typically experience a rise in long-term yields, but EMEs, such as Turkey, Russia, Brazil, and South Africa, experience a decrease in the yields. However, the spillover effects on other asset classes vary largely in magnitude but not in direction. For instance, the estimated effects are stronger on EME currencies than on AE currencies. Appreciation pressures are particularly significant for emerging countries, such as South Africa, Brazil, Poland, Hungary, and Turkey. Finally, for equity markets, spillovers are particularly significant for Brazil and advanced European countries (France, Italy, and Spain).

We construct box plots (Fig. 9) for each of the four country-specific financial variables to present a visual summary of the cross-country variations in the estimated immediate responses of foreign asset prices to reductions in the US mortgage and term spreads. In Fig. 9, the bottom and top of each box show the 25th and 75th percentiles of each group's immediate responses, respectively. Spillover estimate ranges are represented by the top and bottom whiskers. Figure 9 shows that the cross-country variation in the responses of foreign asset prices to the US spread shocks is sizable, particularly in the case of mortgage spread shocks. The estimated immediate responses to the term spread shock vary in magnitude and sign across countries. However, in the case of mortgage spread shock, the responses vary in magnitude across countries, except for long-term yields. Moreover, the foreign assets react more strongly to the mortgage spread shock than to the term spread shock (see also Appendix Figs. 13 and 14 for this interesting finding). Figure 10 shows the cross-country variations within country groups (AEs and EMEs) in the estimated immediate responses of foreign asset prices. This figure presents clear-cut evidence that cross-country variation within country groups is substantial, and the estimated immediate responses largely vary in magnitude. This variation is particularly pronounced for the estimated responses of long-term bond yields to US UMP measures for each country group. In this case, the responses vary in magnitude and sign. Figure 10 also shows that

${ }^{27}$ See Chudik and Fratzscher (2011) and Yildirim (2016) for the effects of a positive VIX shock on international financial markets. 


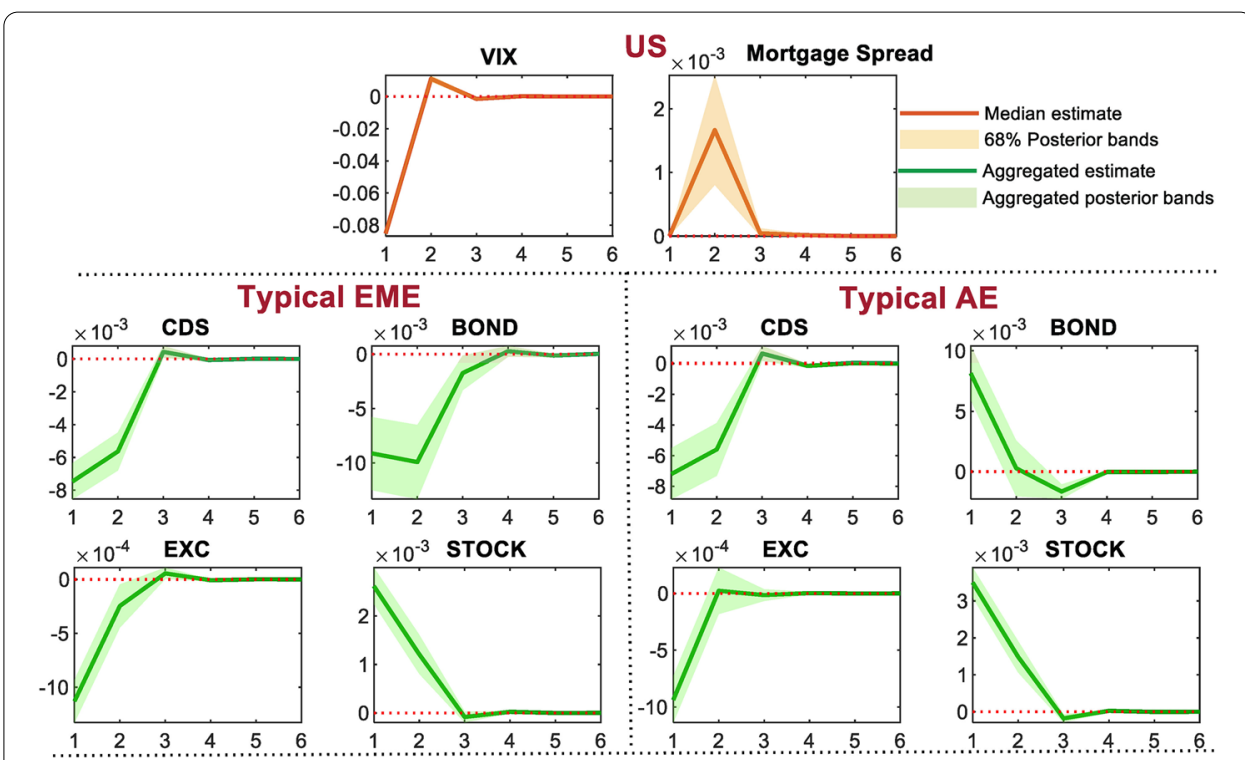

Fig. 7 Effects of a negative VIX shock on typical EME and AE financial variables. Notes: The upper panel shows the country-level (US) impulse responses to a negative VIX shock along with the $68 \%$ posterior probability bands. The lower panels indicate the average responses (Typical EME and AE) to the VIX shock. The average impulse response functions are calculated as a simple arithmetic average of the country-specific impulse response functions of 20 EMEs and 20 AEs. The country-level impulse responses to a negative VIX shock are available from the authors upon request

the responses of EMEs to US UMP are more profound than those of AEs-notably for two asset classes, namely, sovereign CDS and FX. Furthermore, the heterogeneity in the estimated exchange rate responses is more sizable across EMEs, likely indicating differences in the monetary policy (exchange rate regimes) across emerging countries. From another aspect, the median responses of foreign financial variables, except for long-term yield, have the expected sign for the two US UMP indicators.

Overall, based on the box plots in Fig. 10, our results reveal substantial cross-country heterogeneities in international financial spillovers within each country group. These results are consistent with those of the recent growing literature, triggered mainly by the stylized fact of emerging financial markets' heterogeneous reaction to the tapering talks. A growing number of studies in this literature documented a cross-country differentiation within EMEs and AEs in terms of the international spillovers of US UMP. For instance, Ahmed et al. (2017), Bowman et al. (2015), and Aizenman et al. (2016) revealed that EMEs react heterogeneously to external shocks from the US. By contrast, Yildirim (2016) focused on differentiation across a subgroup of EMEs (the Fragile Five) and found significant cross-country heterogeneity across the subgroup. Additionally, Dedola et al. (2017), Chen et al. (2016), and Hausman and Wongswan (2011) regarded the spillovers of US MP to EMEs and AEs. They found that a substantial cross-country variation exists in financial spillovers within EMEs and AEs. 

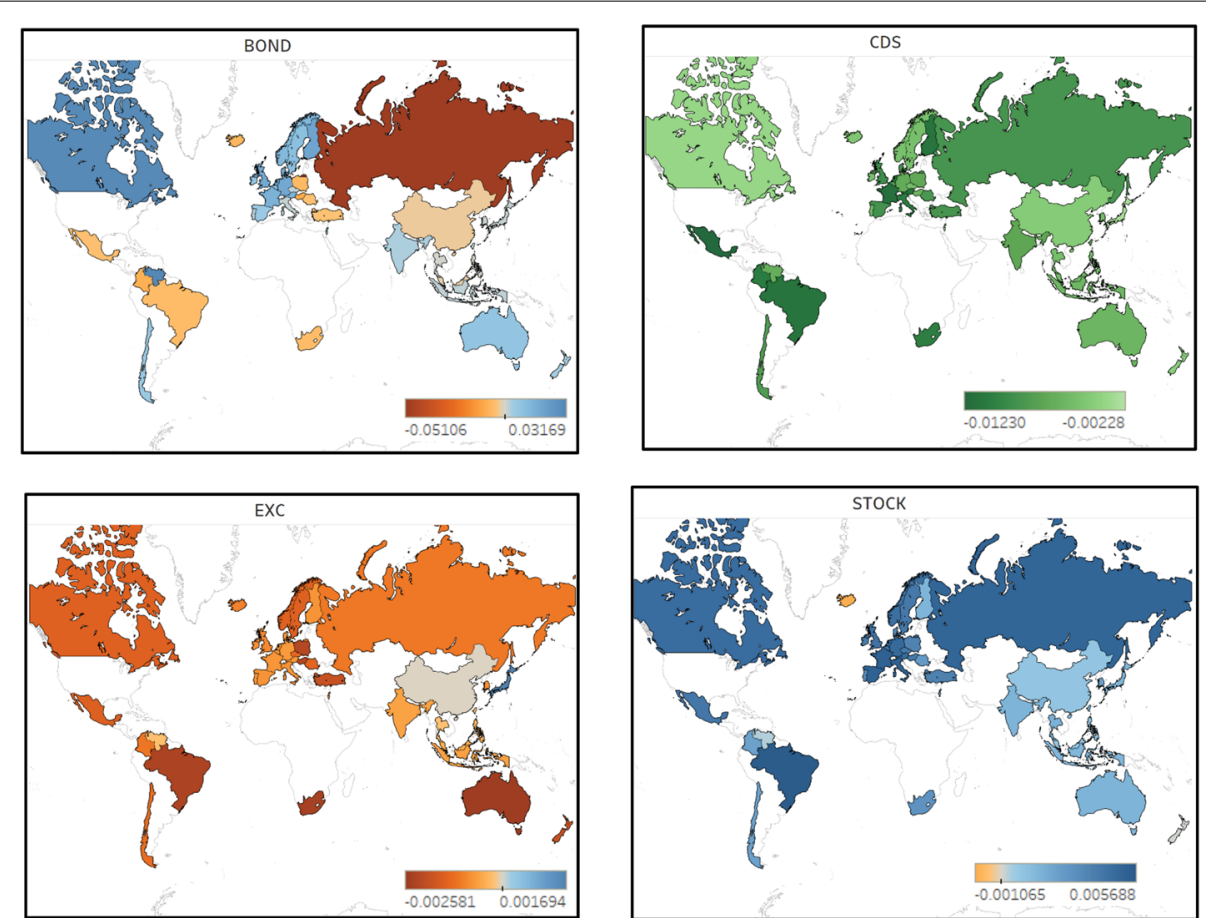

Fig. $8 \mathrm{Immediate}$ responses of foreign financial markets to a US UMP tool (mortgage spread). Notes: The panels_BOND, CDS, EXC, and STOCK - represent the immediate effect of US mortgage spread shocks on the foreign long-term yields (measured by 5 -year local currency government bond yields), the country risk premium (measured by 5 -year sovereign CDS spreads), the exchange rate (defined as domestic currency units per unit in US dollars), and the equity prices (measured by the benchmark index), respectively. Each panel is colorized based on the magnitude and sign of the effect
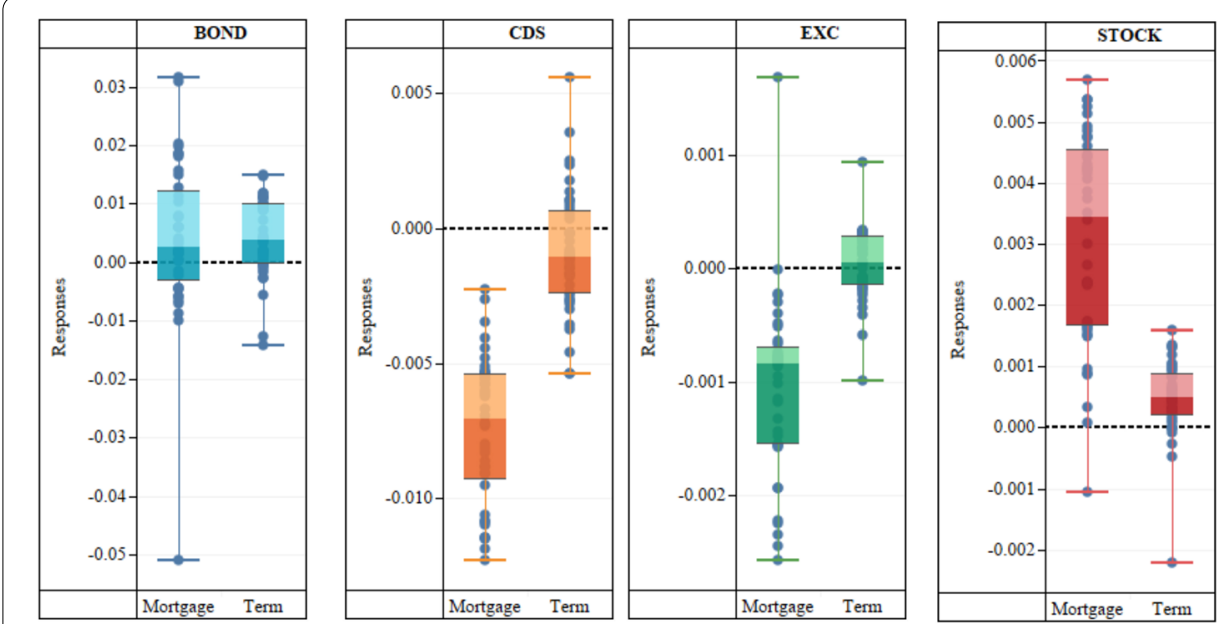

Fig. 9 Distribution of immediate responses to US mortgage and term spread shocks

\section{Robustness}

In this section, we perform two robustness exercises. First, we extend our empirical model by adding a new US variable to the model, that is, the Fed's balance sheet holdings 

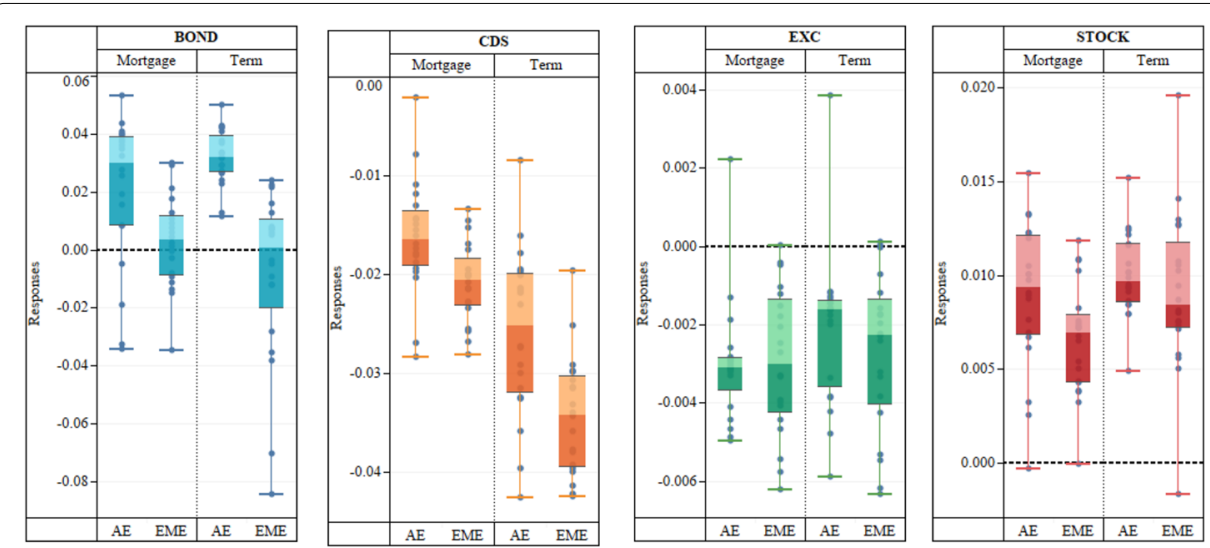

Fig. 10 Distribution of immediate responses to US mortgage and term spread shocks: Cross-country differentiations within EMEs and AEs

of MBS and TS. Second, we use two different US interest rate spreads to check whether our main results depend on the definition of US interest rate spreads.

\section{Extension of the model with the Fed's asset purchases}

We extend the US block with the MBS and TS held outright by the Fed. The objectives are to examine how the Fed's MBS and TS holdings affect mortgage and term spreads, respectively, and to check the robustness of our findings by looking at spillovers from other UMP instruments, such as the Fed's balance sheet holdings of MBS and TS, to international financial markets. Moreover, to conduct this robustness exercise, we change the frequency of variables in the EME (AE) and the US blocks from daily to weekly as data on the MBS and TS holdings are available in weekly frequency. With this extension, the vector of US variables includes three variables:

$$
\Delta x_{t}^{F}=\left\lceil\Delta \operatorname{asset}_{i t}^{U S}, \Delta \text { spread }_{i t}^{U S}, \Delta v_{i x}^{U S}\right\rceil^{\prime},
$$

where $\triangle a s s e t_{i t}^{U S}$ indicates the log first difference of an asset (MBS or TS) held outright by the Fed-subscript $i$ represents each of the two assets held outright by the US monetary authority.

In this extended model, the stance of US UMP is captured through Fed's security (MBS and TS) holdings. On the basis of Blinder (2010) argument, we assume that the MBS holdings decrease the mortgage spread, whereas the TS holdings reduce the term spread (Fig. 2). Hence, we estimate our weekly SVAR models separately for each combination of US UMP instruments, including MBS holdings-mortgage spread and TS holdingsterm spread. The asset purchase shocks are identified by restricting $B_{0}^{F F}$ to be the lower triangular matrix $\left(b_{12}=b_{13}=b_{23}=0\right)$. This form of $B_{0}^{F F}$ suggests that US UMP (MBS or TS holdings) contemporaneously affects interest rate spreads (mortgage or term) and the VIX but responds to changes in financial markets (spreads and VIX) with a lag. In 
sum, in the extended model, the identification of asset purchase shocks can be demonstrated as follows ${ }^{28}$ :

$$
\left(\begin{array}{l}
u_{i t}^{\Delta a s s e t} \\
u_{i t}^{\Delta s p r e a d} \\
u_{t}^{\Delta V I X} \\
u_{i t}^{\Delta r} \\
u_{i t}^{\Delta e} \\
u_{i t}^{\Delta s} \\
u_{i t}^{\Delta \rho}
\end{array}\right)=\left(\begin{array}{ccc|cccc}
1 & 0 & 0 & 0 & 0 & 0 & 0 \\
b_{21} & 1 & 0 & 0 & 0 & 0 & 0 \\
b_{31} & b_{32} & 1 & 0 & 0 & 0 & 0 \\
\hline b_{41} & b_{42} & b_{43} & 1 & b_{45} & b_{46} & b_{47} \\
b_{51} & b_{52} & b_{53} & b_{54} & 1 & b_{56} & b_{57} \\
b_{61} & b_{62} & b_{63} & b_{64} & b_{65} & 1 & b_{67} \\
b_{71} & b_{72} & b_{73} & b_{74} & b_{75} & b_{76} & 1
\end{array}\right)\left(\begin{array}{l}
\varepsilon_{i t}^{\text {asset shock }} \\
\varepsilon_{i t}^{\text {spread shock }} \\
\varepsilon_{t}^{V I X ~ s h o c k} \\
\varepsilon_{i t}^{\Delta r} \\
\varepsilon_{i t}^{\Delta e} \\
\varepsilon_{i t}^{\Delta s} \\
\varepsilon_{i t}^{\Delta \rho}
\end{array}\right)
$$

Figure 11 depicts the corresponding impulse responses. An increase of 1 standard deviation in the Fed's MBS holdings has statistically and economically significant effects on the mortgage spread and the VIX index. The MBS shock decreases the mortgage spread and the VIX index. This result is consistent with that of Wang (2019) and Hancock and Passmore (2011) and the stylized fact illustrated in Fig. 2. From another aspect, the TS shock also reduces the term spread and the VIX index. However, the effects are not statistically significant. These findings are consistent with the stylized fact documented in Sect. 2 and with Blinder (2012), emphasizing that purchasing private sector securities, such as MBS, to reduce risk premiums is much more potent. However, decreasing the term spread through TS purchases may be a weak tool.

The results documented above justify our benchmark empirical analysis with the US spread shocks. Additionally, Fig. 11 depicts the spillover effects of asset purchase (MBS or TS) shocks. Such US UMP shocks produce international financial spillovers the same as that of spread shocks. Hence, our findings remain unchanged when an extended model with an alternative (low-frequency) measure of US UMP is considered.

\section{Alternative (high-frequency) measures of US UMP}

We re-estimate our daily SVAR model with two alternative measures of US spread shocks to check the robustness of our findings. We use a different long-term spread, namely, the corporate spread, ${ }^{29}$ following Chen et al. (2016), and a short-term spread, namely, the commercial paper spread. ${ }^{30}$ Thus, we consider the important fact that the Fed's QE policy also reduces the short-term spread (see Blinder (2010)). Figure 12 presents the corresponding results, which indicate that US UMP influences international financial markets, regardless of which measure of US spread shocks is used. However,

\footnotetext{
${ }^{28}$ Alternatively, as in the baseline model, we also impose zero restrictions on the home block. In this regard, $B_{0}^{H H}$ is also restricted to be lower triangular. Though this results in a just-identified model, it does not change our findings. The corresponding results are available upon request.

29 The corporate spread is calculated as the difference between the US BAA corporate bond rate and the 10-year US Treasury yield.

30 The commercial paper spread is defined as the spread between the interest rates on the 3-month financial commercial paper and 3-month Treasury bills.
} 


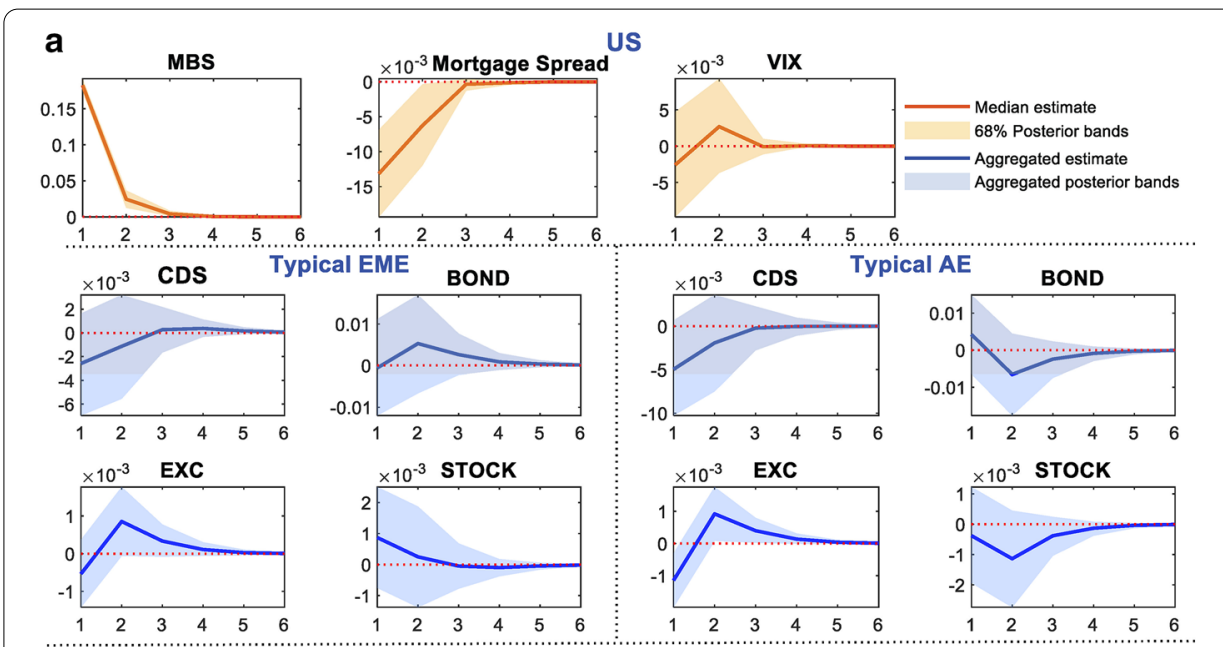

b
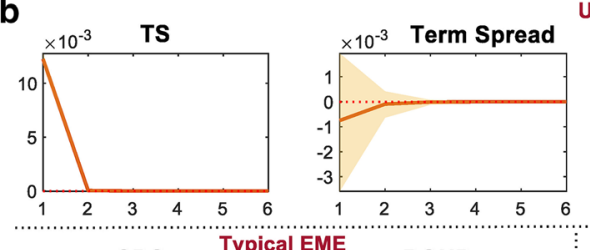

US
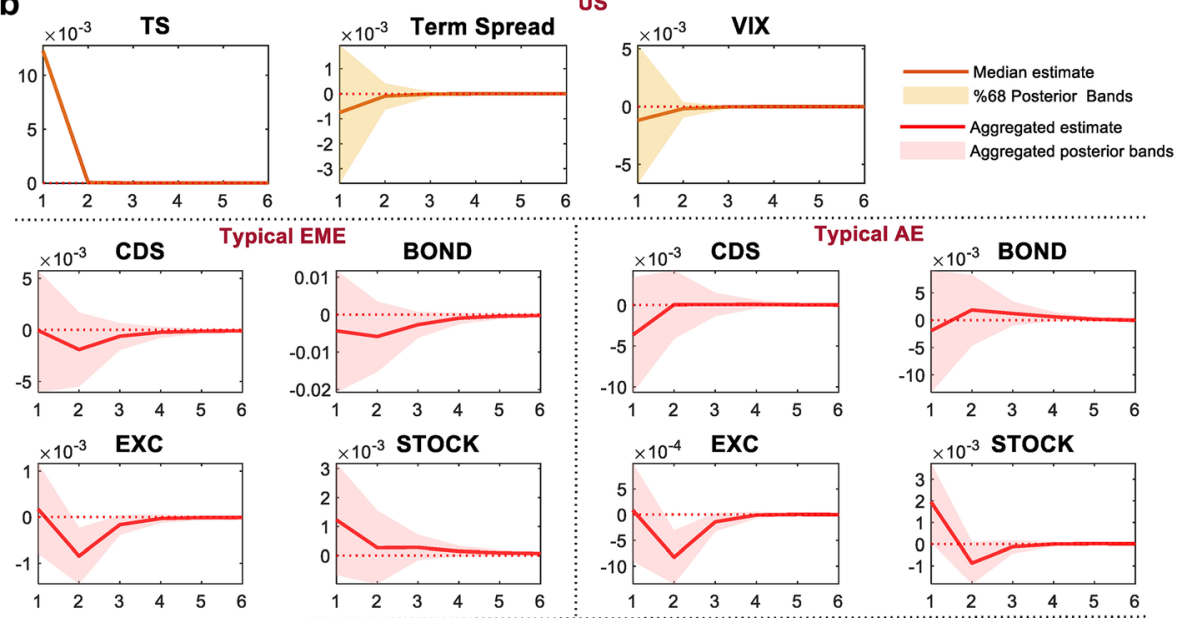

Fig. 11 Responses to US UMP indicators (the Fed's MBS and TS holdings). a Responses of US mortgage spread, global risk appetite, and typical foreign financial markets to a US MBS shock. Notes: The upper panel shows the country-level (US) impulse responses to US MBS shocks along with the $68 \%$ posterior probability bands. The lower panels indicate the average responses (Typical EME and AE) to such shocks. The average impulse response functions are calculated as a simple arithmetic average of the country-specific impulse response functions of $20 \mathrm{EMEs}$ and $20 \mathrm{AEs}$. The country-level impulse responses to MBS shocks are available from the authors upon request. $\mathbf{b}$ Responses of US term spread, global risk appetite, and typical foreign financial markets to a US TS shock. Notes: The upper panel shows the country-level (US) impulse responses to US TS shocks along with the $68 \%$ posterior probability bands. The lower panels indicate the average responses (Typical EME and AE) to such shocks. The average impulse response functions are calculated as a simple arithmetic average of the country-specific impulse response functions of 20 EMEs and $20 \mathrm{AEs}$. The country-level impulse responses to TS shocks are available from the authors upon request

the two spread shocks, mortgage and corporate shocks, have much more profound effects on international financial markets.

\section{Conclusion}

This study presents two sets of results regarding the effects of US UMP on EMEs and AEs. The first set illustrates financial spillovers from US mortgage spread shocks, and the second exposes spillovers resulting from US term spread shocks. 


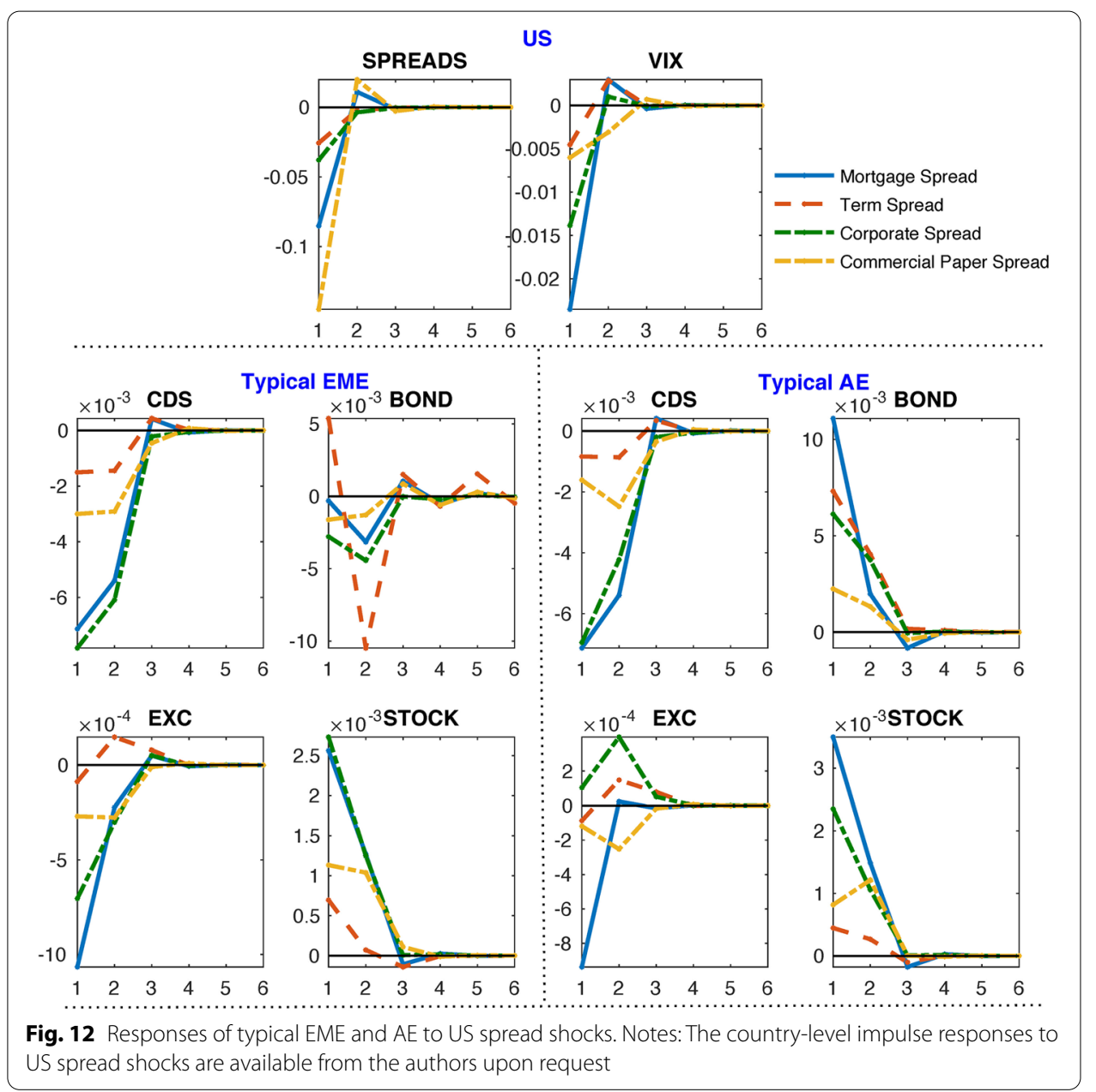

We apply a six-variable SVAR model to reveal the international spillover effect of US UMP. The choice of variables for the US and EME (AE) blocks is mainly guided by the international transmission mechanism of US UMP proposed by the risk-taking channel. Advocates of the risk-taking channel noted that an expansionary US UMP encourages investors to take more risk and reshape their portfolios. Hence, investors' risk-taking behavior is changed, and capital inflows to the rest of the world are boosted, thereby transmitting US UMP measures to other countries' financial markets. To examine these potential effects of US UMP, in our six-variable SVAR model, we use two US variables - an indicator of US UMP (term or mortgage spread) and a measure of risk appetite (VIX) - and four EME (AE) variables, namely, a measure of long-term interest rate, an index of equity prices, a nominal bilateral exchange rate, and a measure of country risk premium.

Our empirical analysis reveals several crucial findings. First, US UMP affects EMEs and AEs by altering investors' risk appetites, which is consistent with the arguments of Rey, Shin, Bernanke, and others regarding the importance of the risk-taking channel. Second, the two US spread shocks, mortgage and term spread shocks, have similar effects on foreign financial markets, which vary across countries and within the EME and AE country groups. Specifically, a US spread shock leads to a decline in country risk 
premiums, a rise in stock prices, an appreciation in local currencies, and a fall in longterm yields in AEs and particularly in EMEs. Moreover, these effects are more intense in the case of the US mortgage spread, indirectly implying that the Fed's LSAP operations (e.g., MBS purchases), which lower the mortgage spread, have larger international financial spillover effects. In other words, the spillover effects of US UMP depend on the kind of assets the Fed purchases. This result is consistent with the argument of MacDonald (2017); that is, the type of asset purchased by the Fed is an important determinant of how EME asset prices are affected by US UMP.

To check the robustness of our benchmark SVAR model, we perform two robustness exercises. First, we extend our empirical model by adding another US UMP variablethe Fed's balance sheet holdings of MBS and TS - to the model. Second, we use two different US interest rate (corporate and commercial paper) spreads to determine whether our main results depend on the definition of US interest rate spreads. We verify that our main findings remain robust to assumptions regarding the specification of US UMP measures.

Our findings are consistent with the literature. That is, an expansionary US monetary policy decreases the VIX index ${ }^{31}$ and accordingly raises market participants' risk appetite, triggers portfolio inflows to the rest of the world, leads to increases in foreign asset prices, and appreciates domestic currencies against the US dollar.

Some policy suggestions from the above-highlighted findings are that market participants and policymakers may consider the following: (i) US UMP has strong and statistically significant spillover effects on EMEs and AEs; (ii) such effects are dependent on the instrument the Fed uses; and (iii) such effects vary considerably across countries and across and within country groups, EMEs and AEs. Hence, as MacDonald emphasizes, policymakers and investors in EMEs and AEs should consider, anticipate, and plan for spillovers from the Fed and should be aware of the types of assets being purchased by the Fed.

In sum, different US expansionary policy instruments have varying spillover effects on EMEs and AEs in terms of size, scale, and outcome. In this sense, policymakers and market participants should consider all these differences when making decisions regarding the spillover effects of US UMP.

Our paper also has a limitation. The study did not directly capture the spillover effects of the US monetary policy on the monetary policy of countries examined because, during our sample period, most of the countries were conducting macroprudential policies. Thus, finding a common instrument for macroprudential policies conducted is very difficult, if not impossible. Finding an instrument that can be used as a common measure of the macroprudential policy across countries would be very productive research.

Admittedly, as it is common in the mainstream conclusion section in the economics literature, our conclusion section also lacks a grand theory. ${ }^{32}$

\footnotetext{
${ }^{31}$ See Bekaert et al. (2013), Rey (2016), Anaya et al. (2017), Gambacorta et al. (2014), Bruno and Shin (2015), Tillmann (2016), Dedola et al. (2017); Lee et al. (2017), Kuttner (2018).

32 See Eriksson (2014) for the discussion regarding the Policy Relevance of Grand Theory.
} 


\section{Appendix}

See Table 4, Figs. 13 and 14.

Table 4 The point estimates of the SVAR parameters

\section{Panel A: US mortgage spread shocks}

Estimated Structural Parameters

EMEs b31 b32 b41 b42 b51 b52 b61 b62 $\begin{array}{llllllllll}\text { BRA.. } & 0,03 & 0,03 & 0,02 & 0,13 & -0,01 & -0,02 & -0,04 & -0,19\end{array}$ CHILE $0,06-0,02 \quad 0,01 \quad 0,06 \quad 0,00-0,02-0,03-0,17$

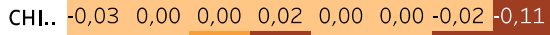
$\begin{array}{lllllllll}\text { COL.. }-0,05 & 0,00 & 0,01 & 0,05 & 0,00 & -0,02 & -0,05 & -0,22\end{array}$ $\begin{array}{llllllllll}\text { CZE.. } & 0,04 & -0,04 & 0,03 & 0,06 & -0,01 & -0,02 & 0,00 & -0,15\end{array}$ HUN.. 0,01 $-0,15 \quad 0,02 \quad 0,06-0,01-0,03-0,01-0,11$

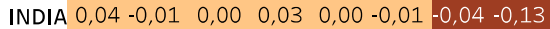
$\begin{array}{llllllllllll}\text { IND.. } & 0,08 & -0,11 & 0,00 & 0,03 & 0,00 & -0,01 & -0,04 & -0,08\end{array}$ MAL..-0,02 $0,02 \quad 0,01 \quad 0,01 \quad 0,00-0,01-0,03-0,08$ $\begin{array}{lllllllllll}\text { MEX..-0,01 } & -0,03 & 0,02 & 0,10 & 0,00 & -0,02 & -0,06 & -0,16\end{array}$

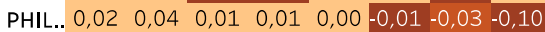
POL.. $-0,03-0,02 \quad 0,02 \quad 0,05-0,01-0,03-0,01-0,15$ $\begin{array}{lllllllllllll}\text { RO.. } & -0,06 & 0,13 & 0,01 & 0,05 & -0,01 & -0,02 & -0,05 & -0,13\end{array}$ $\begin{array}{llllllllll}\text { RUS.. }-0,43 & -0,42 & 0,03 & 0,07 & -0,01 & -0,02 & -0,03 & -0,17\end{array}$ S. A.. $0,00-0,06 \quad 0,01 \quad 0,05-0,01-0,03-0,05-0,12$ $\begin{array}{llllllllll}\text { S. K.. } & 0,00 & 0,02 & 0,01 & 0,03 & 0,00 & -0,01 & -0,02 & -0,09\end{array}$ $\begin{array}{lllllllllll}\text { TAl.. } & 0,00 & 0,04 & 0,01 & 0,02 & 0,00 & 0,00 & -0,05 & -0,13\end{array}$ $\begin{array}{lllllllllll}\text { THA.. } & 0,02 & -0,03 & 0,01 & 0,03 & 0,00 & 0,00 & -0,04 & -0,08\end{array}$ $\begin{array}{llllllllllll}\text { TUR.. } & 0,16 & -0,15 & 0,01 & 0,05 & -0,01 & -0,02 & -0,03 & -0,15\end{array}$

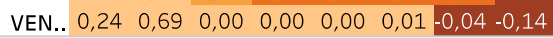

Estimated Structural Parameters

AEs b31 b32 b41 b42 b51 b52 b61 b62

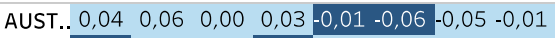

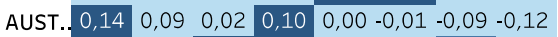
BELG.. $0,13 \quad 0,01 \quad 0,02 \quad 0,10 \quad 0,00-0,01-0,06-0,06$ $\begin{array}{lllllllllllll}\text { CAN.. } & 0,29 & 0,22 & 0,02 & 0,10 & -0,01 & -0,02 & -0,01 & -0,06\end{array}$ $\begin{array}{lllllllllllll}\text { DEN.. } & 0,14 & 0,17 & 0,02 & 0,07 & 0,00 & -0,01 & -0,07 & -0,10\end{array}$

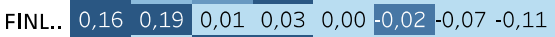
$\begin{array}{llllllllllllll}\text { FRA.. } & 0,14 & 0,06 & 0,02 & 0,11 & 0,00 & -0,01 & -0,10 & -0,08\end{array}$ $\begin{array}{lllllllllllll}\text { GER.. } & 0,14 & 0,13 & 0,02 & 0,10 & 0,00 & -0,01 & -0,03 & -0,11\end{array}$ $\begin{array}{lllllllllll}\text { ICEL.. }-0,12 & 0,07 & -0,02 & 0,01 & 0,00 & -0,02 & -0,04 & -0,04\end{array}$ $\begin{array}{lllllllllllllll} & \text { IREL.. } & 0,15 & -0,05 & 0,02 & 0,11 & 0,00 & -0,02 & -0,04 & -0,07\end{array}$ $\begin{array}{lllllllllll}\text { ISRE.. } & 0,06 & 0,03 & 0,01 & 0,06 & 0,00 & -0,01 & 0,01 & -0,11\end{array}$ $\begin{array}{llllllllllllll}\text { ITALY } & 0,08 & 0,04 & 0,02 & 0,11 & 0,00 & -0,01 & -0,07 & -0,07\end{array}$ $\begin{array}{lllllllll}\text { JAPAN } 0,01 & 0,01 & 0,01 & 0,03 & 0,01 & 0,02 & 0,00 & -0,09\end{array}$ $\begin{array}{lllllllllllll}\text { NET.. } & 0,17 & 0,11 & 0,02 & 0,10 & 0,00 & -0,01 & -0,09 & -0,09\end{array}$ $\begin{array}{llllllllllll}\text { NEW .. } & 0,02 & 0,05 & 0,00 & 0,01 & -0,01 & -0,04 & -0,03 & -0,06\end{array}$ $\begin{array}{lllllllllllllllll}\text { NOR.. } & 0,09 & 0,11 & 0,02 & 0,09 & -0,01 & -0,02 & -0,03 & -0,07\end{array}$ $\begin{array}{lllllllllllllll}\text { POR.. } & 0,10 & -0,05 & 0,01 & 0,07 & 0,00 & -0,01 & -0,03 & -0,05\end{array}$

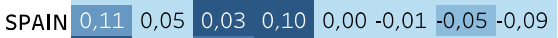
$\begin{array}{lllllllllllllll}\text { SWE.. } & 0,07 & 0,10 & 0,01 & 0,10 & -0,01 & -0,01 & -0,03 & -0,04\end{array}$ $\begin{array}{lllllllllll}\text { UK } & 0,14 & 0,10 & 0,02 & 0,09 & 0,00 & -0,01 & -0,06 & -0,05\end{array}$

\section{Panel B: US term spread shocks}

Estimated Structural Parameters

EMEs b31 b32 b41 b42 b51 b52 b61 b62 $\begin{array}{llllllllllll}\text { BRA.. } & 0,35 & 0,03 & 0,02 & 0,14 & 0,00 & -0,02 & -0,02 & -0,21\end{array}$ $\begin{array}{lllllllll}\text { CHILE- } 0,10 & 0,00 & 0,00 & 0,06 & 0,01 & -0,02 & 0,05 & -0,19\end{array}$

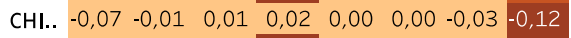
$\begin{array}{llllllllllllll}\text { COL.. } & 0,05 & -0,01 & -0,01 & 0,05 & 0,00 & -0,02 & -0,01 & -0,24\end{array}$ $\begin{array}{llllllllll}\text { CZE.. } & 0,14 & -0,03 & 0,03 & 0,07 & 0,01 & -0,03 & 0,00 & -0,15\end{array}$ $\begin{array}{llllllllll}\text { HUN..-0,34 } & -0,14 & 0,01 & 0,07 & 0,00 & -0,04 & -0,04 & -0,11\end{array}$ $\begin{array}{lllllllll}\text { INDIA } & 0,00 & 0,00 & 0,01 & 0,03 & 0,00 & -0,01 & -0,03 & -0,14\end{array}$ $\begin{array}{lllllllllll}\text { IND.. } & 0,44 & -0,09 & 0,02 & 0,03 & 0,00 & -0,01 & 0,00 & -0,09\end{array}$ $\begin{array}{llllllllll}\text { MAL... }-0,02 & 0,01 & -0,01 & 0,01 & 0,00 & -0,01 & -0,04 & -0,09\end{array}$ $\begin{array}{llllllllllll}\text { MEX.. } & 0,19 & -0,04 & 0,03 & 0,10 & 0,01 & -0,03 & -0,05 & -0,18\end{array}$ $\begin{array}{lllllllll}\text { PHIL.. } 0,15 & 0,04 & 0,00 & 0,01 & -0,01 & -0,01 & -0,08 & -0,11\end{array}$ \begin{tabular}{llllllllll} 
POL.. $-0,12$ & $-0,04$ & 0,03 & 0,06 & 0,02 & $-0,03$ & 0,08 & $-0,15$ \\
\hline
\end{tabular} $\begin{array}{lllllllll}\text { RO.. } & -0,62 & 0,11 & 0,00 & 0,05 & 0,00 & -0,03 & -0,09 & -0,15\end{array}$ $\begin{array}{lllllllll}\text { RUS.. } & 0,68 & -0,60 & 0,05 & 0,08 & 0,01 & -0,02 & 0,13 & -0,19\end{array}$ $\begin{array}{llllllll}\text { S. A.. }-0,01 & -0,06 & 0,00 & 0,06 & 0,00 & -0,03 & -0,09 & -0,14\end{array}$ $\begin{array}{llllllllll}\text { S. K.. } & 0,06 & 0,02 & 0,02 & 0,04 & 0,00 & -0,01 & 0,02 & -0,10\end{array}$ $\begin{array}{llllllllll}\text { TAl.. } & 0,03 & 0,04 & 0,00 & 0,02 & 0,00 & 0,00 & -0,12 & -0,15\end{array}$ $\begin{array}{llllllllll}\text { THA.. }-0,01 & -0,03 & -0,01 & 0,04 & -0,01 & 0,00 & -0,07 & -0,09\end{array}$ $\begin{array}{llllllllll}\text { TUR.. } & 0,00 & -0,09 & 0,03 & 0,05 & -0,01 & -0,02 & 0,03 & -0,16\end{array}$

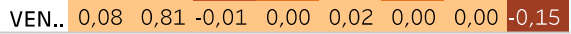

$$
\begin{array}{ll}
\hline \text { p-value (EMEs) } & \\
\hline 0.0000 & 0.1000
\end{array}
$$

Estimated Structural Parameters

AEs b31 b32 b41 b42 b51 b52 b61 b62 \begin{tabular}{ll|llllllll} 
AUST.. 0,14 & 0,06 & $-0,01$ & 0,03 & 0,02 & $-0,06$ & 0,00 & $-0,03$
\end{tabular} AUST.. $0,33 \quad 0,14-0,01 \quad 0,11 \quad 0,02-0,01 \quad 0,04-0,15$ BELG.. 0,41 $0,05-0,02 \quad 0,11 \quad 0,01-0,01-0,06-0,08$ $\begin{array}{llllllllllllll}\text { CAN.. } & 0,51 & 0,30 & 0,00 & 0,10 & 0,02 & -0,02 & 0,00 & -0,06\end{array}$ $\begin{array}{lllllllllllllll}\text { DEN.. } & 0,33 & 0,22 & -0,01 & 0,07 & 0,02 & -0,01 & -0,04 & -0,12\end{array}$ FINL.. $0,35 \quad 0,24-0,01 \quad 0,03 \quad 0,02-0,02-0,18-0,14$ $\begin{array}{llllllllllll}\text { FRA.. } & 0,40 & 0,10 & -0,01 & 0,12 & 0,02 & -0,01 & 0,00 & -0,11\end{array}$ $\begin{array}{llllllllllll}\text { GER.. } & 0,30 & 0,17 & 0,00 & 0,10 & 0,02 & -0,01 & 0,09 & -0,12\end{array}$ $\begin{array}{llllllllll}\text { ICEL.. } & 0,21 & 0,02 & -0,09 & 0,01 & -0,03 & -0,02 & -0,13 & -0,06\end{array}$ $\begin{array}{llllllllllll}\text { IREL.. }-0,07 & 0,01 & 0,02 & 0,11 & 0,02 & -0,02 & -0,02 & -0,08\end{array}$ $\begin{array}{lllllllll}\text { ISRE.. }-0,02 & 0,05 & 0,02 & 0,06 & -0,01 & -0,01 & 0,10 & -0,10\end{array}$

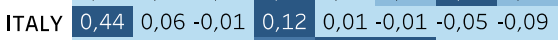
$\begin{array}{lllllllllll}\text { JAPAN } & 0,03 & 0,02 & -0,01 & 0,03 & 0,03 & 0,02 & 0,03 & -0,09\end{array}$ $\begin{array}{lllllllllllllllll}\text { NET.. } & 0,36 & 0,16 & 0,00 & 0,11 & 0,02 & -0,01 & -0,06 & -0,12\end{array}$ $\begin{array}{llllllllllll}\text { NEW .. } & 0,06 & 0,05 & -0,01 & 0,01 & 0,00 & -0,05 & 0,22 & -0,07\end{array}$ $\begin{array}{lllllllllll}\text { NOR.. } & 0,18 & 0,14 & 0,01 & 0,10 & 0,00 & -0,02 & 0,10 & -0,09\end{array}$ $\begin{array}{lllllllllllll}\text { POR.. } & 0,45 & -0,01 & 0,00 & 0,08 & 0,01 & -0,01 & 0,01 & -0,06\end{array}$ $\begin{array}{lllllllllll}\text { SPAIN } & 0,42 & 0,08 & 0,00 & 0,11 & 0,01 & -0,01 & 0,03 & -0,11\end{array}$ $\begin{array}{lllllllllllllll}\text { SWE.. } & 0,05 & 0,12 & 0,00 & 0,10 & 0,01 & -0,02 & 0,13 & -0,06\end{array}$ $\begin{array}{lllllllllllllllllll}\text { UK } & 0,32 & 0,14 & 0,00 & 0,10 & 0,01 & -0,01 & -0,15 & -0,06\end{array}$ p-value (AEs)

$0.0000 \quad 0.1000$

This table presents the country-level estimates of the related structural parameters for US spread shocks (Mortgage [Panel A] and Term [Panel B]). The statistical significance of the estimated parameters is highlighted by color scales: Each cell is colorized based on the level of statistical significance. A darker (lighter) color represents higher (lower) statistical significance 


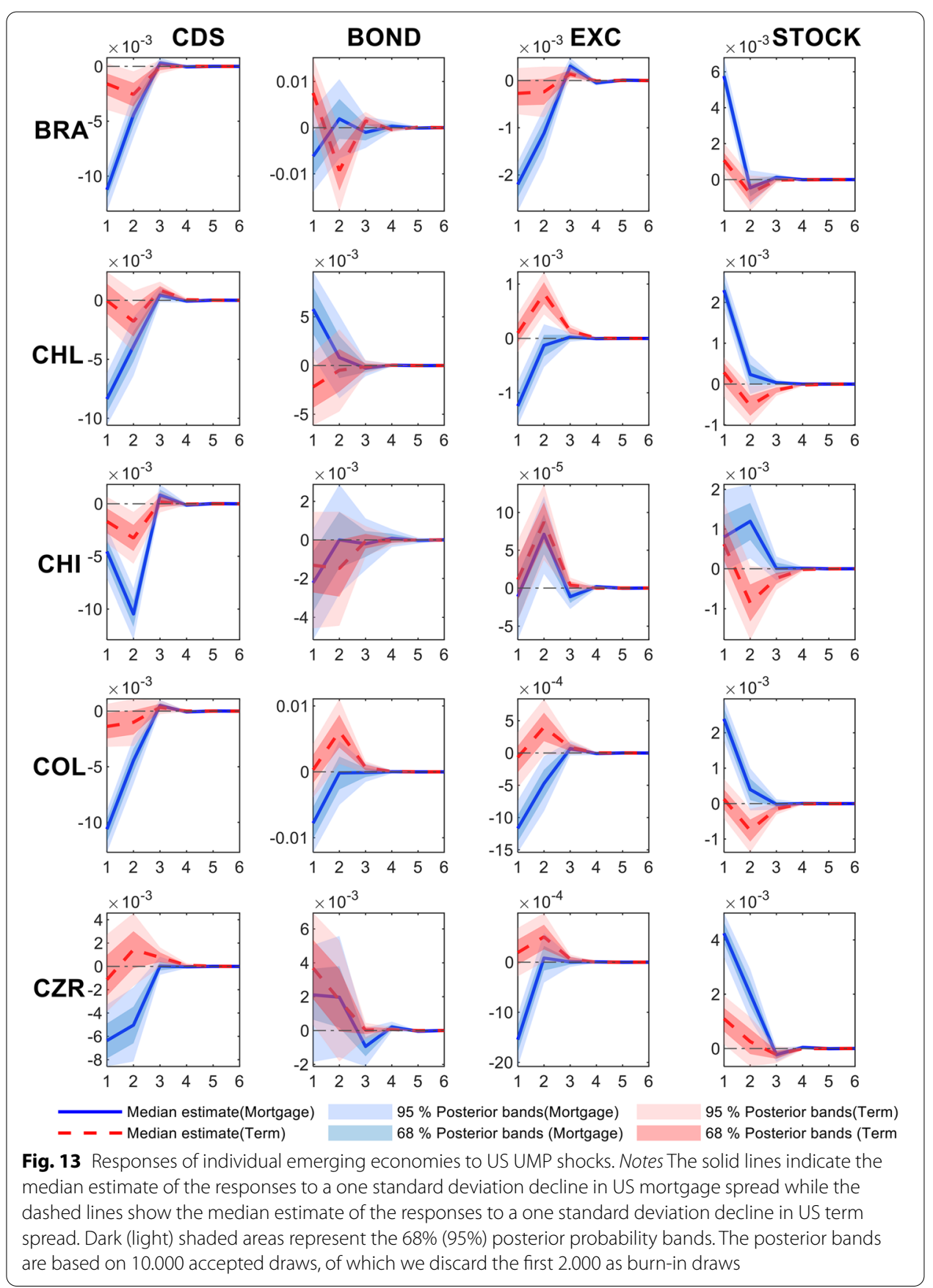




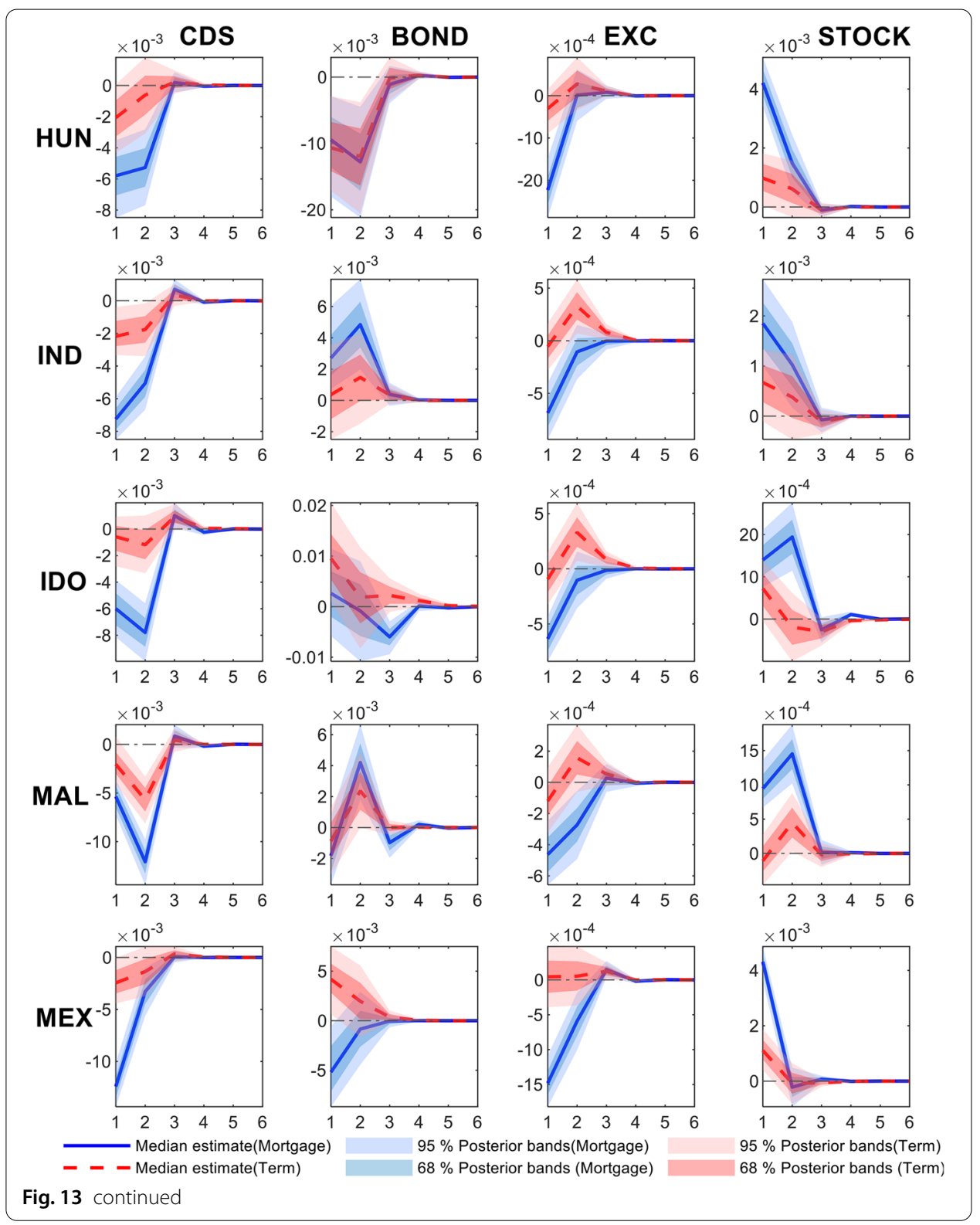


Yildirim and Ivrendi Financ Innov

(2021) 7:86

Page 30 of 38

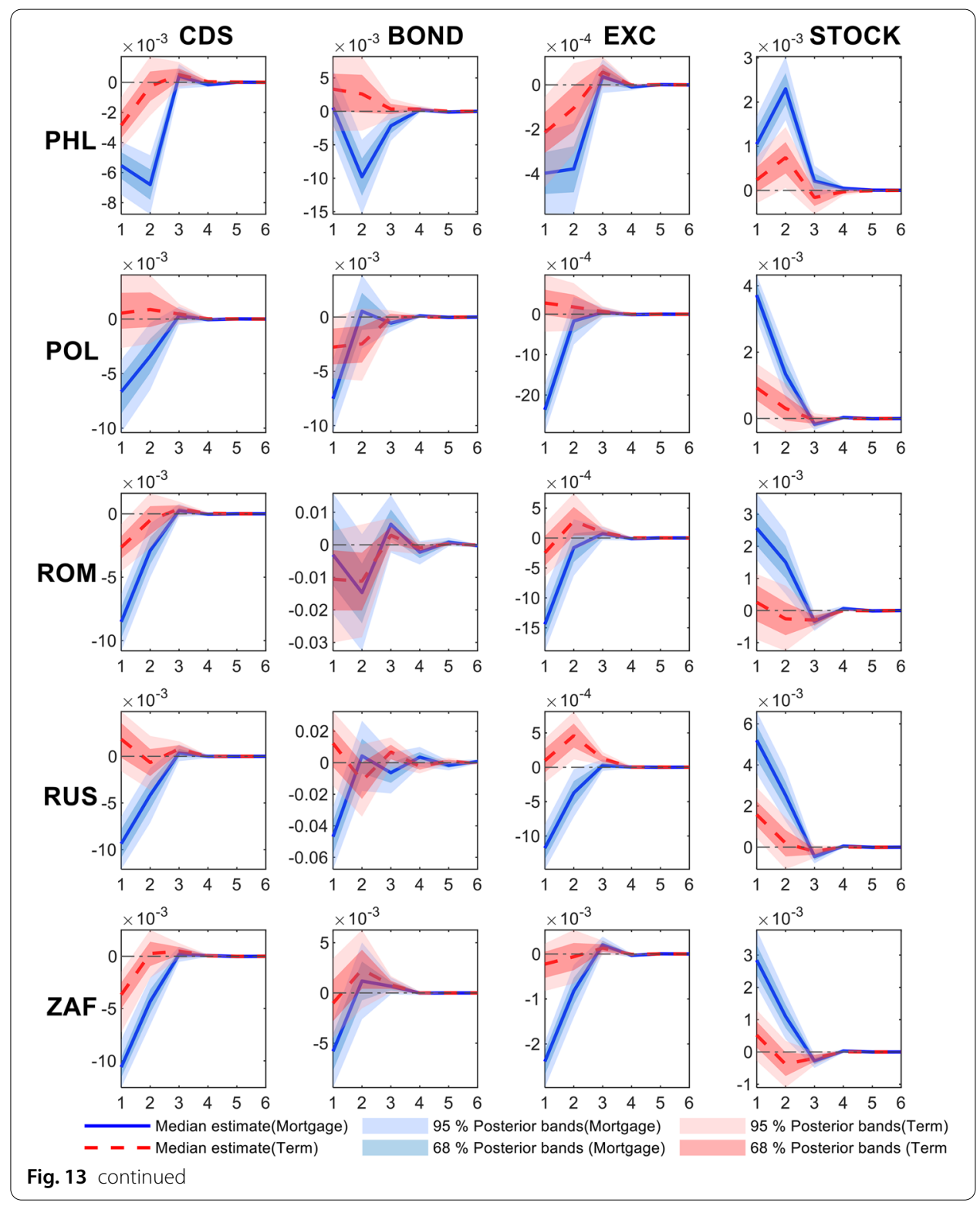




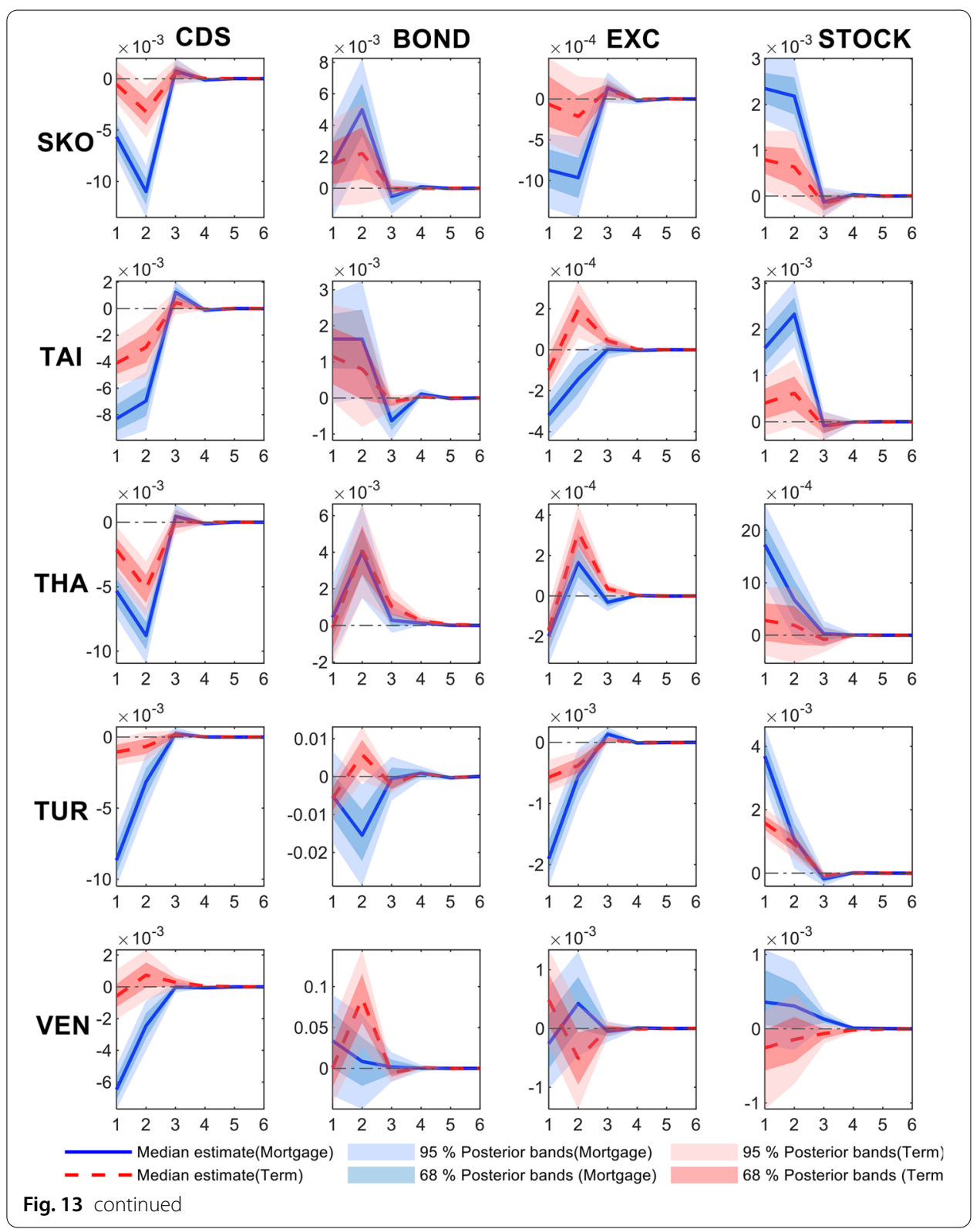




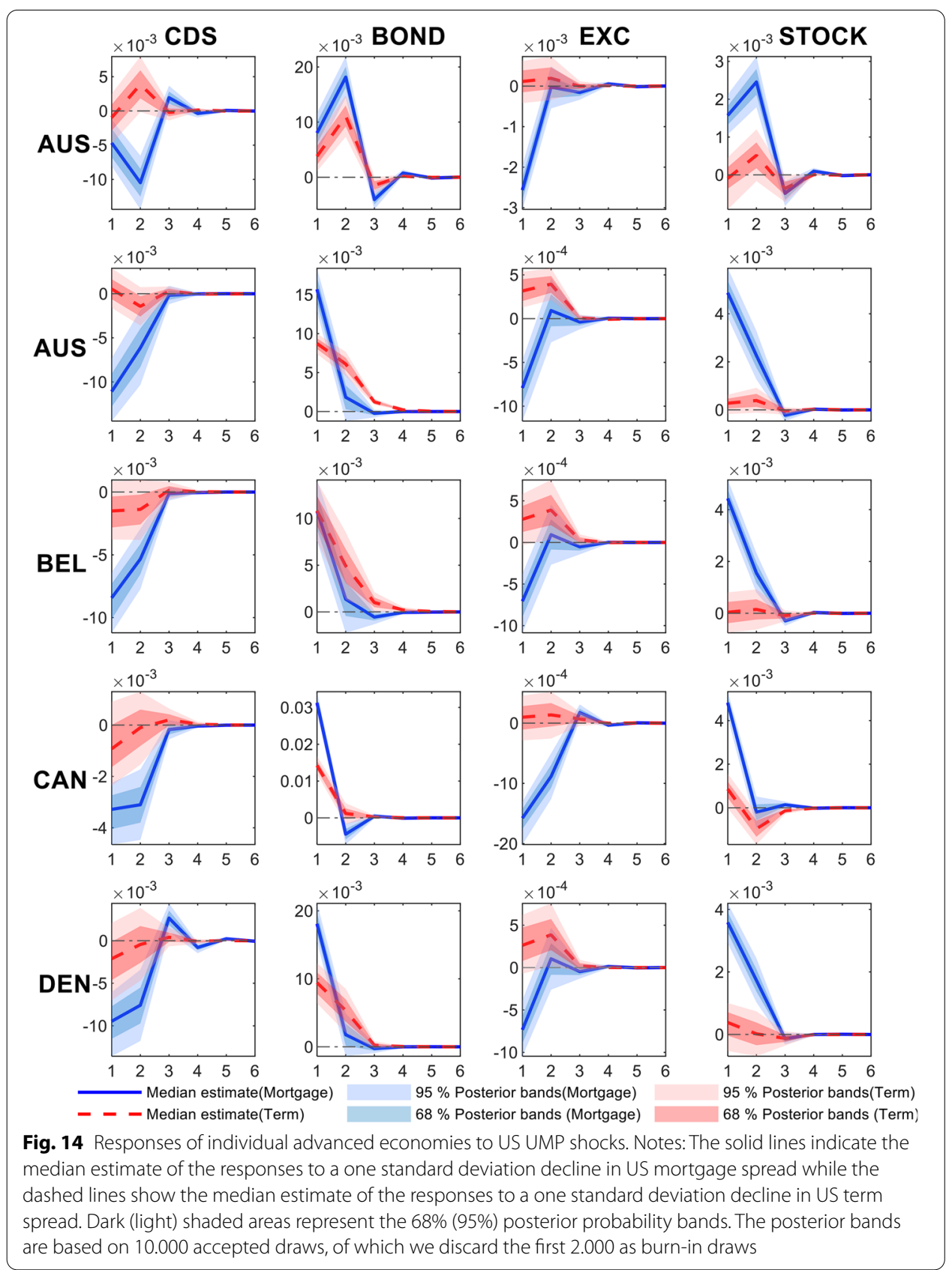




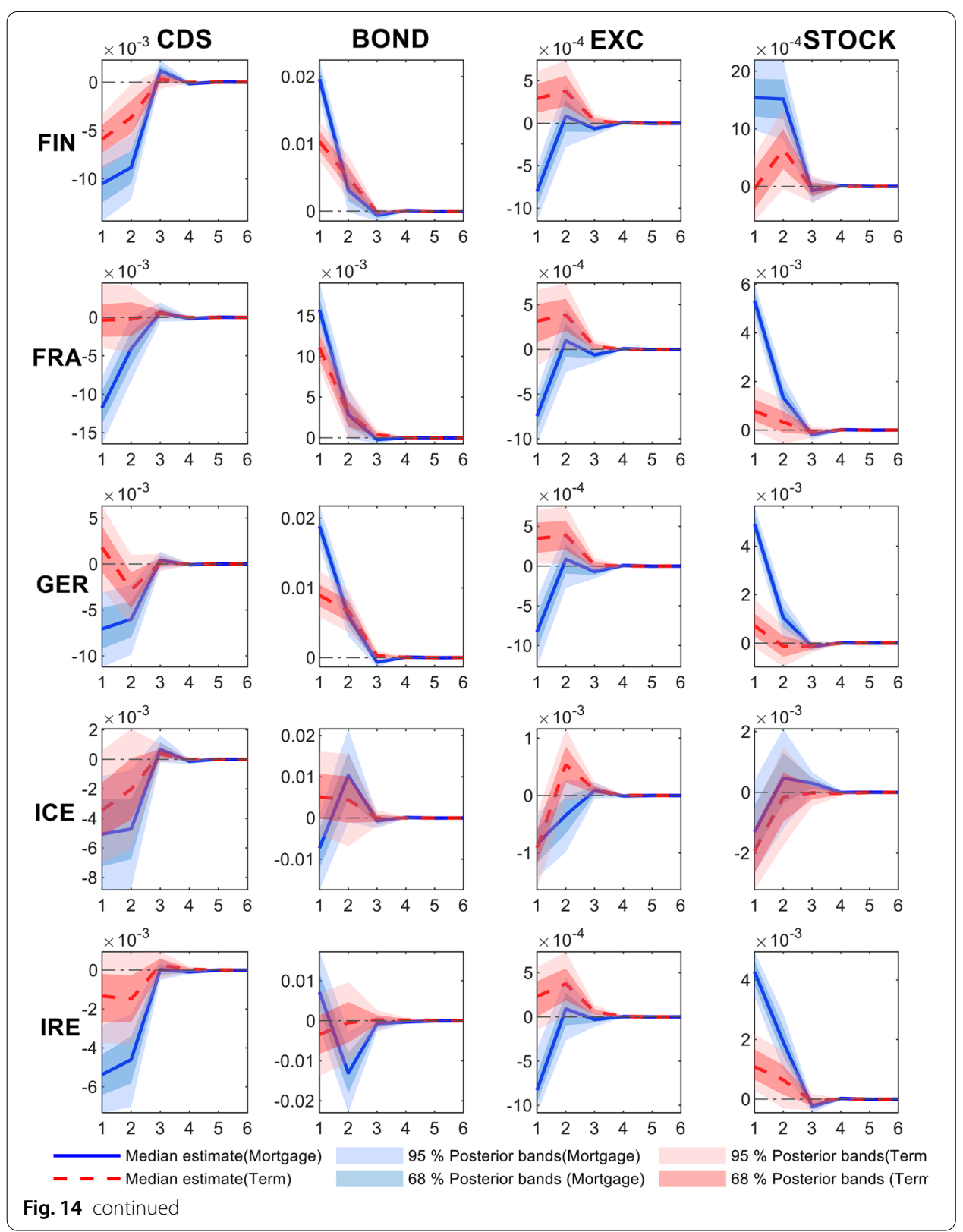




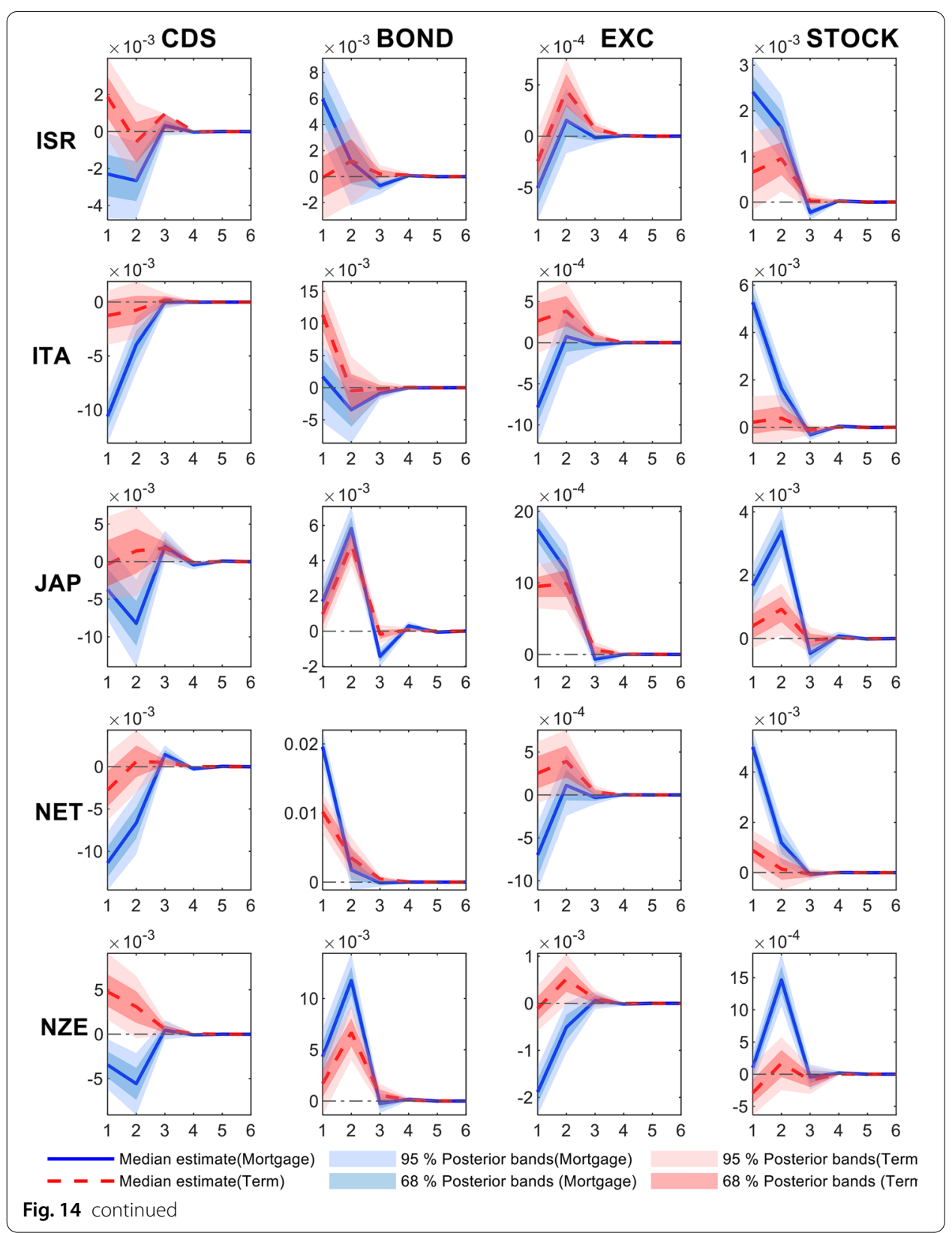




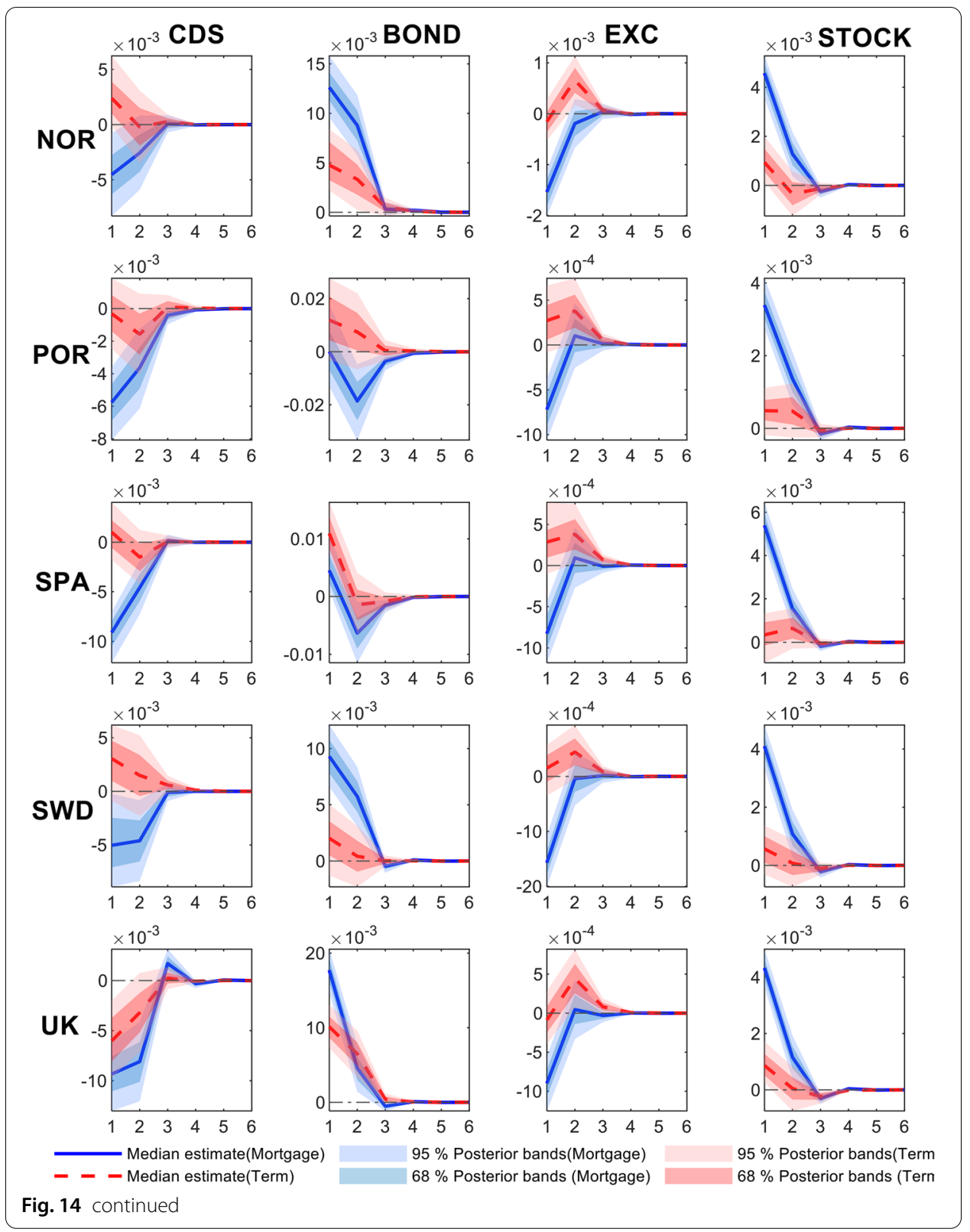

\section{Abbreviations}

Fed: Federal Reserve; LSPAs: Large Scale Asset Purchases; QE: Quantitative Easing; MBS: Mortgage-Backed Securities; TS: Treasury Securities; UMP: Unconventional monetary policy; SVAR: Structural vector autoregression; EMEs: Emerging markets economies; AEs: Advanced economies; VIX: CBOE Volatility Index; CDS: Credit default swaps; SUR: Seemingly unrelated regressions; FX: Foreign exchange; US: United States; ZLB: Zero lower bound; MCMC: Markov Chain Monte Carlo.

\section{Acknowledgements}

The authors would like to thank the five anonymous referees of this journal for their constructive comments. The first author ,ZY, also thanks Gencer Yildirim for his suggestions about the graphical visualization of the results and Anadolu University Scientific Research Commission for the financial support (Grant number: 1605E282).

\section{Authors' contributions}

ZY: Conceptualization, Methodology, Data collection, Software, Writing- original draft preparation, Writing- review and editing, Literature review, Formal analysis, Resources, Visualization, Revision, Funding Acquisition. MI: Discussion of the results, Literature review, Revision. The author(s) read and approved the final manuscript. 


\section{Authors' information}

Zekeriya Yildirim is an Associate Professor in the Department of Economics at Anadolu University. His Ph.D. thesis won Unal Aysal Doctoral Dissertation Competition Award granted by Economic Research Foundation of Turkey in 2012. Yildirim's research interests include open-economy macroeconomics and international financial markets. His recent works focus on the spillovers of external financial conditions to emerging market economies and the role of exchange rate fluctuations. He has published in Energy, Economic Modelling, Economic Research-Ekonomska Istrazivanja, Economics: The Open-Access, Open-Assessment E-Journal, Central Bank Review, Journal of Economic Studies, and Istanbul Journal of Economics.

Mehmet Ivrendi is a Professor of Economics at Pamukkale University in Denizli/Turkey. His research focuses on monetary policy, exchange rate, stock market and applied time series. His some selected studies are published on Applied Economics, Economic Modelling, Applied Economics Letters, Emerging Market Finance \&Trade, Economics Discussion Papers, Journal of Economic Studies, International Journal of Finance \& Economics. https://www.pau.edu.tr/iktisat/tr/sayfa/ mehmet-ivrendi. https://www.researchgate.net/profile/Mehmet-Ivrendi

\section{Funding}

Funding was provided by Anadolu University Scientific Research Project Commission (Grant number: 1605E282).

\section{Availability of data and materials}

The data for this paper is available upon request.

\section{Declarations}

\section{Competing interests}

The authors declare that they have no competing interests.

\section{Author details}

${ }^{1}$ Department of Economics, Faculty of Economics and Administrative Sciences, Anadolu University, Tepebasi, Eskisehir 26470, Turkey. ${ }^{2}$ Department of Economics, Faculty of Economics and Administrative Sciences, Pamukkale University, Kınıkl, Denizli 20070, Turkey.

Received: 4 February 2021 Accepted: 30 September 2021

Published online: 05 November 2021

\section{References}

Aharon DY, Umar Z, Vo XV (2021) Dynamic spillovers between the term structure of interest rates, bitcoin, and safe-haven currencies. Financ Innov $7(1): 1-25$

Ahmed S, Coulibaly B, Zlate A (2017) International financial spillovers to emerging market economies: how important are economic fundamentals? J Int Money Financ 76:133-152

Aizenman J, Binici M, Hutchisonc MM (2016) The transmission of federal reserve tapering news to emerging financial markets. Int J Central Bank

Anaya P, Hachula M, Offermanns CJ (2017) Spillovers of US unconventional monetary policy to emerging markets: the role of capital flows. J Int Money Financ 73:275-295

Apostolou A, Beirne J (2018) Volatility spillovers of unconventional monetary policy to emerging market economies. Econ Model 78:118-129

Avdjiev S, Bruno V, Koch C, Shin HS (2019) The dollar exchange rate as a global risk factor: evidence from investment. IMF Econ Rev 67:1-23

Bauer MD, Neely CJ (2014) International channels of the Fed's unconventional monetary policy. J Int Money Financ 44:24-46

Baumeistera C, Benatib L (2013) Unconventional monetary policy and the great recession: estimating the macroeconomic effects of a spread compression at the zero lower bound. Int J Cent Bank 9(2):165-212

Bekaert G, Hoerova M, Duca ML (2013) Risk, uncertainty and monetary policy. J Monet Econ 60(7):771-788

Bernanke BS (2017) Federal reserve policy in an international context. IMF Econ Rev 65(1):1-32

Bhattarai S, Chatterjee A, Park WY (2021) Effects of US quantitative easing on emerging market economies. J Econ Dyn Control 122:104031

Bhattarai S, Neely C (2016) A survey of the empirical literature on US unconventional monetary policy: Federal Reserve Bank of St. Louis, Research Division

Blinder AS (2010) Quantitative easing: entrance and exit strategies. Federal Reserve Bank St. Louis Rev 92(6):465-479

Blinder AS (2012) Revisiting monetary policy in a low-inflation and low-utilization environment. J Money Credit Bank 44:141-146

Borio C, Zhu H (2012) Capital regulation, risk-taking and monetary policy: a missing link in the transmission mechanism? J Financ Stab 8(4):236-251

Bowman D, Londono JM, Sapriza H (2015) US unconventional monetary policy and transmission to emerging market economies. J Int Money Financ 55:27-59

Bruno V, Shin HS (2015) Capital flows and the risk-taking channel of monetary policy. J Monet Econ 71:119-132

Buckle RA, Kim K, Kirkham H, McLellan N, Sharma J (2007) A structural VAR business cycle model for a volatile small open economy. Econ Model 24(6):990-1017

Canova F (2005) The transmission of US shocks to Latin America. J Appl Economet 20(2):229-251 
Carrillo JA, Elizondo R, Hernández-Román LG (2020) Inquiry on the transmission of US aggregate shocks to Mexico: a SVAR approach. J Int Money Financ 104:102148

Cecioni M, Ferrero G, Secchi A (2011) Unconventional monetary policy in theory and in practice. Mimeo

Chao X, Kou G, Peng Y, Alsaadi FE (2019) Behavior monitoring methods for trade-based money laundering integrating macro and micro prudential regulation: a case from China. Technol Econ Dev Econ 25(6):1081-1096

Chen Q, Filardo A, He D, Zhu F (2016) Financial crisis, US unconventional monetary policy and international spillovers. J Int Money Financ 67:62-81

Cheng CHJ, Chiu CW (2020) Nonlinear effects of mortgage spreads over the business cycle. J Money Credit Bank 52(6):1593-1611

Chudik A, Fratzscher M (2011) Identifying the global transmission of the 2007-2009 financial crisis in a GVAR model. Eur Econ Rev 55(3):325-339

Cushman DO, Zha T (1997) Identifying monetary policy in a small open economy under flexible exchange rates. J Monet Econ 39(3):433-448

d'Amico S, English W, López-Salido D, Nelson E (2012) The Federal Reserve's large-scale asset purchase programmes: rationale and effects. Econ J 122(564):F415-F446

Dahlhaus T, Hess K, Reza A (2018) International transmission channels of US quantitative easing: evidence from Canada. J Money Credit Bank 50(2-3):545-563

Dai M, Dufourt F, Zhang Q (2013) Large scale asset purchases with segmented mortgage and corporate loan markets. Mimeo

Dedola L, Rivolta G, Stracca L (2017) If the Fed sneezes, who catches a cold? J Int Econ 108:S23-S41

Doan T (2014) RATS User's Guide, version 9. Evanston US: Estima

Doan T (2015) RATS handbook for vector autoregressions. Estima, Evanston, 2nd Edition

ECB (June 2007) Measuring investors'risk appetite. Financial Stability Review, ECB

Eichengreen B, Gupta P (2015) Tapering talk: the impact of expectations of reduced Federal Reserve security purchases on emerging markets. Emerg Markets Rev 25:1-15

Eriksson J (2014) On the policy relevance of grand theory. Int Stud Perspect 15(1):94-108

Feldkircher M, Gruber T, Huber F (2020) International effects of a compression of euro area yield curves. J Bank Financ 113:105533

Feldkircher M, Huber F (2018) Unconventional US monetary policy: new tools, same channels? J Risk Financ Manag 11(4):71

Fratzscher M, Lo Duca M, Straub R (2017) On the international spillovers of US quantitative easing. Econ J 128(608):330-377

Gagnon J, Raskin M, Remache J, Sack BP (2011) Large-scale asset purchases by the Federal Reserve: did they work? Econ Policy Rev (May), 41-59

Gai P, Vause N (2004) Risk appetite: concept and measurement. Financ Stab Rev 17:127-136

Gambacorta L, Hofmann B, Peersman G (2014) The effectiveness of unconventional monetary policy at the zero lower bound: a cross-country analysis. J Money Credit Bank 46(4):615-642

Hamilton JD, Wu JC (2012) The effectiveness of alternative monetary policy tools in a zero lower bound environment. J Money Credit Bank 44:3-46

Hancock D, Passmore W (2011) Did the Federal Reserve's MBS purchase program lower mortgage rates? J Monet Econ 58(5):498-514

Hännikäinen J (2015) Zero lower bound, unconventional monetary policy and indicator properties of interest rate spreads. Rev Financ Econ 26:47-54

Hausman J, Wongswan J (2011) Global asset prices and FOMC announcements. J Int Money Financ 30(3):547-571

Hesse H, Hofmann B, Weber J (2018) The macroeconomic effects of asset purchases revisited. J Macroecon $58: 115-138$

Ho SW, Zhang J, Zhou H (2018) Hot money and quantitative easing: the spillover effects of US Monetary policy on the Chinese Economy. J Money Credit Bank 50(7):1543-1569

Hofmann B, Shim I, Shin HS (2016) Sovereign yields and the risk-taking channel of currency appreciation

Horvath J, Rothman P (2021) Mortgage spreads, asset prices, and business cycles in emerging countries. J Int Money Finance 102370

Huang Y-F (2019) Dynamic responses of real output to financial spreads. Int Rev Econ Financ 62:153-159

Jordà Oे, Schularick M, Taylor AM, Ward F (2019) Global financial cycles and risk premiums. IMF Econ Rev 67(1):109-150

Kalemli-Özcan Ș (2019) US monetary policy and international risk spillovers. National Bureau of Economic Research, No. 26297

Koeda J (2019) Macroeconomic effects of quantitative and qualitative monetary easing measures. J Jpn Int Econ 52:121-141

Kou G, Akdeniz ÖO, Dinçer H, Yüksel S (2021) Fintech investments in European banks: a hybrid IT2 fuzzy multidimensional decision-making approach. Financ Innov 7(1):1-28

Kou G, Chao X, Peng Y, Alsaadi FE, Herrera-Viedma E (2019) Machine learning methods for systemic risk analysis in financial sectors. Technol Econ Dev Econ 25(5):716-742

Krishnamurthy A, Vissing-Jorgensen A (2011) The effects of quantitative easing on interest rates: channels and implications for policy. No. w17555

Kuttner KN (2018) Outside the box: unconventional monetary policy in the great recession and beyond. J Econ Perspect 32(4):121-146

Lee SJ, Liu LQ, Stebunovs V (2017) Risk taking and interest rates: evidence from decades in the global syndicated loan market: International Monetary Fund

Liu P, Theodoridis K, Mumtaz H, Zanetti F (2018) Changing macroeconomic dynamics at the zero lower bound. J Bus Econ Stat 1-14

MacDonald M (2017) International capital market frictions and spillovers from quantitative easing. J Int Money Financ 70:135-156 
Maćkowiak B (2007) External shocks, US monetary policy and macroeconomic fluctuations in emerging markets. J Monet Econ 54(8):2512-2520

Miranda-Agrippino S, Rey H (2020) US monetary policy and the global financial cycle. Rev Econ Stud 87(6):2754-2776

Neely CJ (2015) Unconventional monetary policy had large international effects. J Bank Finance 52:101-111

Nsafoah D, Serletis A (2020) Monetary policy and interest rate spreads. Open Econ Rev 31(3):707-727

Olani A (2020) Dynamic effects of macroeconomic policies on categories of emerging markets'capital inflows. Macroecon Financ Emerg Market Econ 13(1):1-28

Ouyang AY, Guo S (2019) Macro-prudential policies, the global financial cycle and the real exchange rate. J Int Money Financ 96:147-167

Rey H (2015) Dilemma not trilemma: the global financial cycle and monetary policy independence. National Bureau of Economic Research, No. w21162

Rey $\mathrm{H}$ (2016) International channels of transmission of monetary policy and the Mundellian trilemma. IMF Econ Rev 64(1):6-35

Rudebusch G (2018) A review of the fed's unconventional monetary policy. FRBSF Econ Lett 27:1-5

Tillmann P (2016) Unconventional monetary policy and the spillovers to emerging markets. J Int Money Financ 66:136-156

Tule KM, Odonye OJ, Afangideh UJ, Ebuh GU, Udoh EAP, Ujunwa A (2019) Assessing the spillover effects of US monetary policy normalization on Nigeria sovereign bond yield. Financ Innov 5(1):1-16

Walentin K (2014) Business cycle implications of mortgage spreads. J Monet Econ 67:62-77

Wang L (2019) Measuring the effects of unconventional monetary policy on MBS spreads: a comparative study. N Am J Econ Financ 49:235-251

Ward F (2018) Global risk taking, exchange rates, and monetary policy. Working Paper

Yildirim Z (2016) Global financial conditions and asset markets: evidence from fragile emerging economies. Econ Model 57:208-220

Zha T (1999) Block recursion and structural vector autoregressions. J Econ 90(2):291-316

\section{Publisher's Note}

Springer Nature remains neutral with regard to jurisdictional claims in published maps and institutional affiliations.

\section{Submit your manuscript to a SpringerOpen ${ }^{\circ}$ journal and benefit from:}

- Convenient online submission

- Rigorous peer review

- Open access: articles freely available online

- High visibility within the field

- Retaining the copyright to your article

Submit your next manuscript at $\gg$ springeropen.com 